\title{
ASPECTOS ARTÍSTICOS DEL FONDO ANTIGUO DIGITAL DE LA UNIVERSIDAD DE SEVILLA: LOS FRONTISPICIOS DEL SIGLO XVI
}

\author{
José Luis Herrera Morillas* \\ Universidad de Extremadura
}

\begin{abstract}
Resumen: Se recopilan y estudian los frontispicios procedentes del fondo antiguo digital (siglo XVI) de la Universidad de Sevilla. Se propone un modelo de clasificación y análisis. El total de los frontispicios analizados es de 84, que forman parte de las 833 obras de la colección digital del siglo XVI de la Universidad de Sevilla.

Palabras clave: Frontispicios; ilustración; libro antiguo, Universidad de Sevilla.

Title: ARTISTIC ASPECTS OF THE OLD DIGITAL COLLECTION AT THE UNIVERSITY OF SEVILLE: THE ENGRAVED OF THE XVI CENTURY.

Abstract: The engraved of the old digital collection (XVI century) at the University of Seville are located and studied. A classification model and analysis is proposed. The digital collection (XVI century) is made up of 833 books.

Keywords: Engraved; illustration; old book; University of Seville.
\end{abstract}

\section{INTRODUCCIÓN}

Este trabajo se engloba en una investigación que tiene por objeto el estudio de los elementos artísticos de los impresos del siglo XVI de la colección digital de fondo antiguo de la Biblioteca de la Universidad de Sevilla. Se entiende por elementos artísticos las encuadernaciones artísticas y las distintas ilustraciones que pueden presentar los libros impresos antiguos (frontispicios, viñetas, marcas de impresores, iniciales, etc.).

En este artículo se presentan los resultados de los frontispicios o portadas grabadas. Por tanto, el objetivo general de este trabajo consiste en analizar estos elementos del fondo antiguo digital del siglo XVI de la Universidad de Sevilla. Para ello ha sido necesario localizar los frontispicios en el conjunto de obras digitalizadas del siglo XVI y diseñar un método de estudio de los mismos.

En la actualidad el fondo antiguo de la Universidad de Sevilla está integrado por 1.217 manuscritos, 332 incunables y cerca de 60.000 impresos de los siglos XVI al XVIII. A éste también se añaden las obras del siglo XIX (41.049). Este fondo está ligado a la historia de la Universidad y se ha ido formando como consecuencia de donaciones (las primeras de su fundador y profesores), la expulsión de los jesuitas, la Desamortización y la incorporación de otras bibliotecas privadas, sobre todo a partir del siglo XVI. ${ }^{1}$

Esta colección se guarda fundamentalmente en la Biblioteca General Rector Antonio Machado y Núñez y en el Archivo Histórico, aunque también en otras bibliotecas de la Universidad, sobre todo en la de Humanidades y en la del Laboratorio de Arte.

El fondo del siglo XVI sorprende por su volumen, más de 9.000 obras, que reflejan la prosperidad de la ciudad en este periodo. Están representadas las disciplinas del momento (Literatura, Filología, Derecho y Legislación, Teología, Filosofía, Historia, Matemáticas, Astronomía, Cosmografía y Geografía, Medicina, Farmacia, etc.). Una breve muestra de algunos ejemplares significativos pueden ser Las siete Partidas (dos ediciones de Salamanca del taller de los Portonaris); los Elementos de Euclides; tres ediciones de la Geografía de Tolomeo (Venecia, 1511; Norimberga, 1514; Lyon, 1535); varias ediciones de las Tablas alfonsíes; la primera edición tratado de Copérnico De revolutionibus Orbium coelestium (Norimberga, 1543); la Chirugia de Vidio, en su edición prínceps de París 1544 y otros muchos.

Esta sucinta mención no puede acabar sin aludir a los impresos locales salidos de la variada nómina de talleres como los de Jacobo y Juan Cromberger, Varela de Salamanca, Martín de Montesdoca, Sebastián Trujillo, Alonso de la Barrera, Adrea Pescioni, Juan de León, etc. De todos ellos sobresale el taller de los Cromberger con sus tres generaciones: Jacobo el padre, Juan el hijo y Jacobo el nieto. Entre las obras célebres salidas de este taller están: la Suma de geographia de Fernández de Enciso, primer libro impreso en España que habla de América; Visión delectable de la philosophia; o la Vita Christi Cartuxano de Ludolphus de Saxonia.

*jlhermor@unex.es

Recibido: 09-07-2015; 2 ${ }^{\mathrm{a}}$ versión: 13-07-2015; aceptado: 08-09-2015.

HERRERA MORILLAS, JL. Aspectos artísticos del fondo antiguo digital de la Universidad de Sevilla: los frontispicios del siglo XVI. Anales de Documentación, 2015, vol. 18, nº 2. Disponible en: http://dx.doi.org/10.6018/analesdoc.18.2.228341. 
La colección digital está formada actualmente por todos los incunables de la Biblioteca, los impresos sevillanos del siglo XVI y una selección de las obras de mayor relieve de los siglos XVI al XVIII: 833 obras del siglo XVI, 1.652 del siglo XVII, 2.716 del siglo XVIII y 572 del siglo XIX.

El acceso a las obras digitalizadas se puede realizar tanto a través de los registros bibliográficos en el catálogo FAMA <http://fama.us.es/> como directamente en la web fondo antiguo digital $<$ http://fondosdigitales.us.es/fondos/>, configurada a modo de portal, con estas secciones:

-Obras (grupos de obras, obras recientes, joyas de la biblioteca, solicitar digitalización)

-Grabados (grupos de grabados, grabados recientes)

-Hemeroteca histórica

$-\mathrm{B} \log$

-Exposiciones virtuales

-Noticias y novedades

-Suscripciones al boletín

-Enlaces

-Obras destacadas

El apartado "Grupos de obras" permite acceder a las obras a través de 51 opciones o categorías por las que se agrupan las obras: por materias, por siglos, por colecciones, por procedencia, etc.

El estudio de los frontispicios al que se dedica este trabajo hay que situarlo dentro de la evolución de las portadas de los libros. La portada durante el siglo XVI evoluciona desde aquellas en las que la ilustración tiene poca presencia, hasta las portadas ricamente ilustradas como las que se estudian en este artículo. En esta evolución tuvo mucha influencia la implantación del grabado calcográfico, que desplaza a la técnica anterior: el grabado xilográfico. El grabado calcográfico lo introducen en España grabadores extranjeros, sobre todo flamencos y franceses (CornejoVega, 2008, p. 496).

De todas las partes ilustradas del libro la portada es una de las primeras que empiezan a recibir estos elementos con el propósito de hacer los libros más atractivos y valiosos, siguiendo un proceso de embellecimiento progresivo. Señala García Olmedo que:

"La progresiva complicación en la decoración de las portadas llevará durante los siglos XVI y XVII a concebir el libro como un ente asimilable a las otras artes, y adoptar así un modelo arquitectónico que aparece al comienzo del libro y que se asemeja a las fachadas de los edificios o a los retablos de las iglesias de la época. De esta forma se configurará el llamado frontispicio, que no es más que la portada grabada que contiene los datos del libro o la hoja anterior a la portada cuando contiene también motivos grabados” (García Olmedo, 1997, p. 80).

El frontispicio suele estar formado por "una gran estampa calcográfica, que ocupa toda la página, y que ciertamente ha incorporado en la plancha, grabado el título" (Martín, 2004, p. 65), con una doble finalidad: informativa y persuasiva, pues pretende ejercer:

"una poderosa llamada visual que atrae el interés del potencial lector hacia el libro y su contenido, actuando, como han dicho algunos, a modo de puerta que invita a ser traspasada; y, sobre todo, busca la exaltación de unas ideas, personajes o instituciones, normalmente vinculados a los ámbitos de lo político y lo religioso. Y esto es así, y hasta tal punto, que en muchos casos el despliegue propagandístico dificulta la propia funcionalidad informativa de la portada” (Cornejo-Vega, 2008, p. 496).

El origen de los frontispicios parece ser que se remonta a los Países Bajos y en España se introducen en Navarra por impresores como Adrián de Amberes, al que van a seguir otros de la tierra como Miguel de Eguía, Matías Mares y Tomás Porralis (Rodríguez, 2000, p. 169). Aunque aparecen a mediados del siglo XVI, no se generalizan hasta el periodo barroco abarcando desde finales del siglo XVI hasta mediados del siglo XVII. En su elaboración predomina la técnica calcográfica, concretada en tres acciones: el diseño del dibujo, la realización completa del dibujo y su plasmación en la plancha (Reyes, 2003, p. 211). Por ello, en los grabados podemos encontrar que:

"las expresiones delineavit o pinxit se anteponían al nombre del autor del original que se estaba convirtiendo en grabado; ligados a ellas, existían los términos fecit, incidit o incisit, y sculsip que indicaban el nombre del grabador que había realizado la obra de otro artista; en español: lo grabó o go. Completando esta serie se encuentra el término excudit que enlaza con los anteriores y servía de antefirma al editor” (Cabo, 1981, p. 40-63). ${ }^{2}$

La relación entre los diseños de los frontispicios y la arquitectura del momento es estrecha, destacando la influencia del manierismo. En España este movimiento está presente entre 1560 y 1630 ; y sucede algo semejante a lo 
ocurrido en Italia, "el campo constructivo se plasma en investigaciones sobre la dialéctica de las formas, su intersección, sus contracciones y anamorfosis perspectivas” (Muñoz Jiménez, 1992, p. 14).

Los estudios sobre frontispicios del libro antiguo español no son abundantes y, según Civil (2009, p. 519), faltan trabajos de conjunto y los trabajos realizados se acercan al tema indirectamente. Se trata de "algunas monografías sobre grabadores, repertorios de determinados centros de imprenta, también análisis de piezas específicas que abren las obras cumbres de la literatura". 3

\section{METODOLOGÍA}

Los fondos digitalizados son una de las grandes aportaciones de la Sociedad de la Información para facilitar el acceso y estudio de los libros antiguos. Se solucionan los problemas de conservación que implican la manipulación de los originales y se facilita enormemente la observación detenida de las obras gracias a las herramientas que incorporan los programas de navegación.

Las 833 obras que constituyen el fondo digital del siglo XVI de la Universidad de Sevilla constituyen una muestra significativa y representativa de la colección del siglo XVI, pues la selección ha sido realizada por la propia Biblioteca, siguiendo los criterios de incluir todos los impresos sevillanos y una selección de los ejemplares de mayor relieve del resto de los libros.

Para el realizar el estudio de los ejemplares se ha accedido a la sección "grupo de obras" eligiendo la categoría "Libros del siglo XVI". Una vez dentro, el sistema de acceso a los libros está configurado del siguiente modo: se visualiza un listado con todas las obras, que incluye el título, el autor, el año y una imagen en miniatura de la portada (Figura 1).

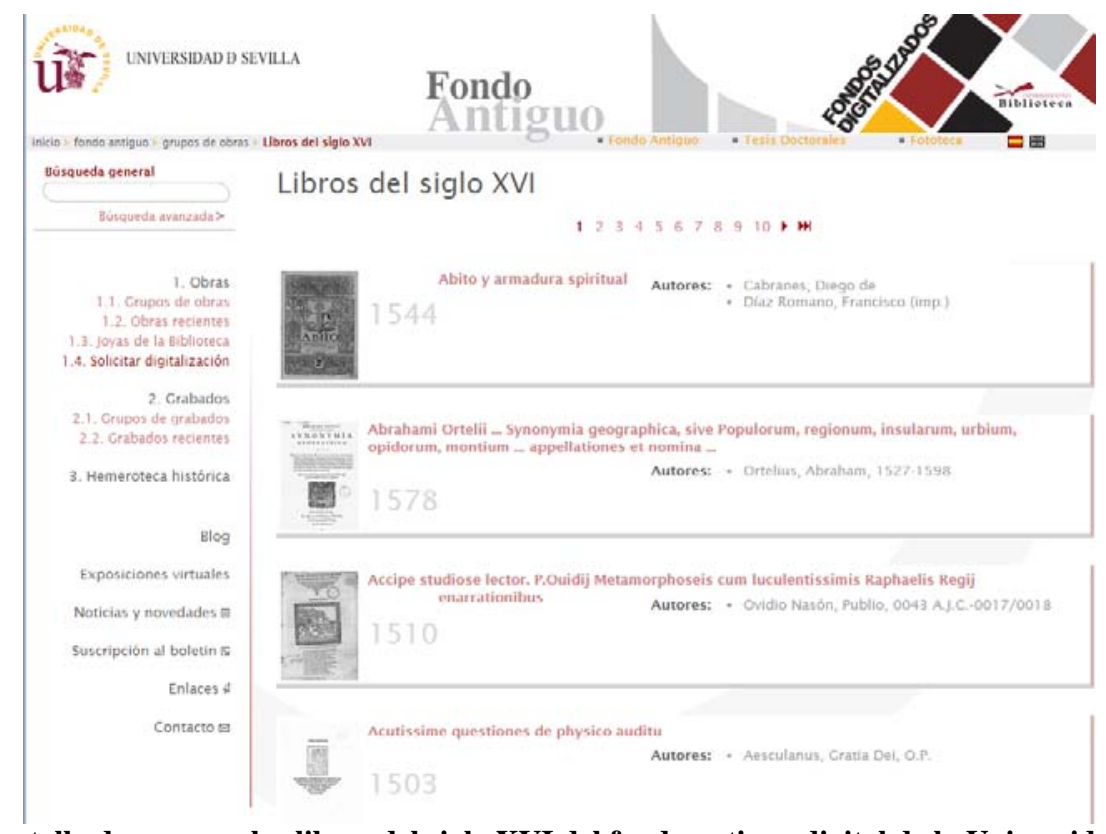

Figura 1: Pantalla de acceso a los libros del siglo XVI del fondo antiguo digital de la Universidad de Sevilla.

El título y la imagen funcionan como link que abren el acceso a la obra digitalizada. La obra se dispone en el centro de la pantalla con las herramientas de navegación. A la izquierda se visualizan los menús de: vistas de la obra (vista detallada, vista amplia, leer, grabados de la obra, miniaturas de la obra) e índice de la obra. A la derecha las opciones de: descargar obra, acceso al registro completo, descargar en distintas modalidades de metadatos y otros datos de la obra como: autor, impresor, etc. (Figura 2). 


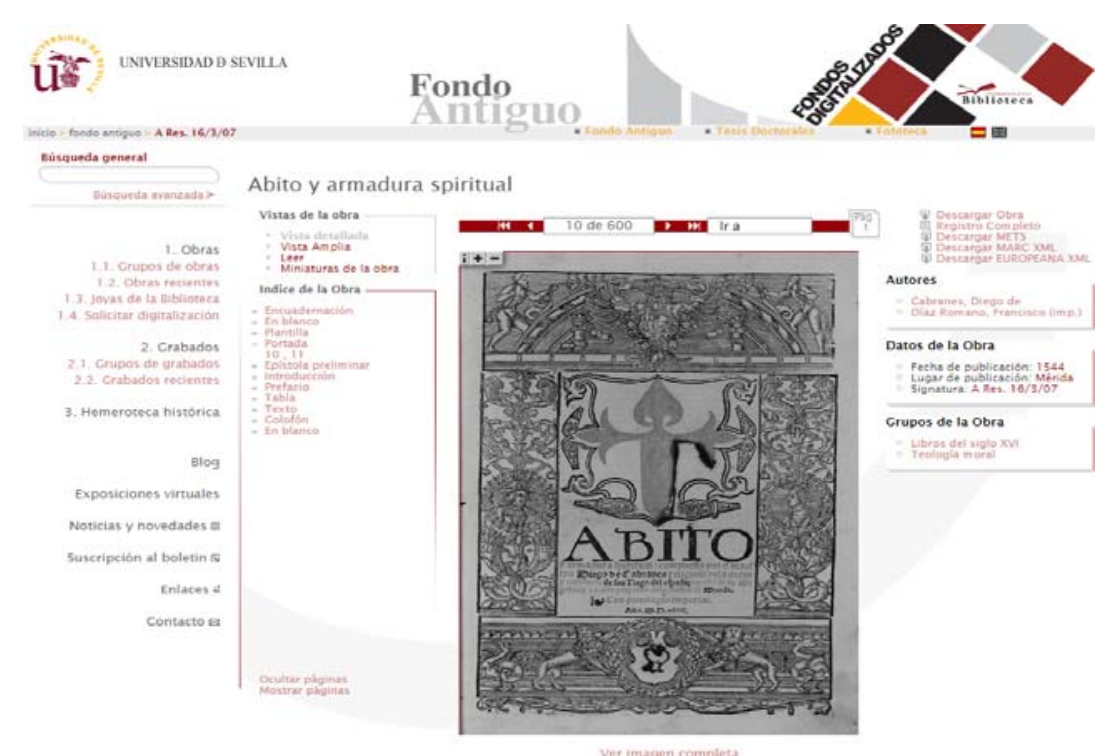

Figura 2: Pantalla de navegación del fondo antiguo digital de la Universidad de Sevilla.

Tras la localización de las portadas de interés y después de una visión de conjunto se detectó que era necesario definir dos grupos:

-Frontispicios con orlas arquitectónicas

-Frontispicios con planchas

Los frontispicios con orlas arquitectónicas en sentido estricto son portadas decoradas con orlas xilográficas, pues la mayoría suelen estar formadas por varios tacos de madera que rodean la parte textual. Pero, debido al motivo de las orlas (elementos arquitectónicos) y al efecto que producen (puerta o arco) se pueden considerar un precedente de los frontispicios realizados con planchas.

Los frontispicios con planchas son los característicos realizados con una plancha normalmente calcográfica.

El trabajo incluye dos apéndices, uno con las imágenes de los frontispicios; y otro con las referencias bibliográficas de las obras que los contienen, extraídas de los registros catalográficos de la Biblioteca. En los dos apéndices, las obras se dividen en dos grupos: frontispicios con orlas arquitectónicas (FO) y frontispicios con planchas (FP). Dentro de cada grupo los elementos se ordenan de forma alfabética por el título. Para identificar cada referencia y cada imagen se utiliza el número ordinal correspondiente seguido de las abreviaturas FO (Frontispicio con orlas arquitectónicas) o FP (Frontispicio con planchas).

Para organizar el análisis de los frontispicios con orlas arquitectónicas, debido a que presentan un esquema muy parecido basado en el diseño de una puerta formada por cuatro elementos: los dos soportes verticales, el basamento y el remate superior (realizado cada uno con un taco diferente), se diseña este esquema de estudio y clasificación:

A. Tipos de soportes verticales que se emplean en las puertas:
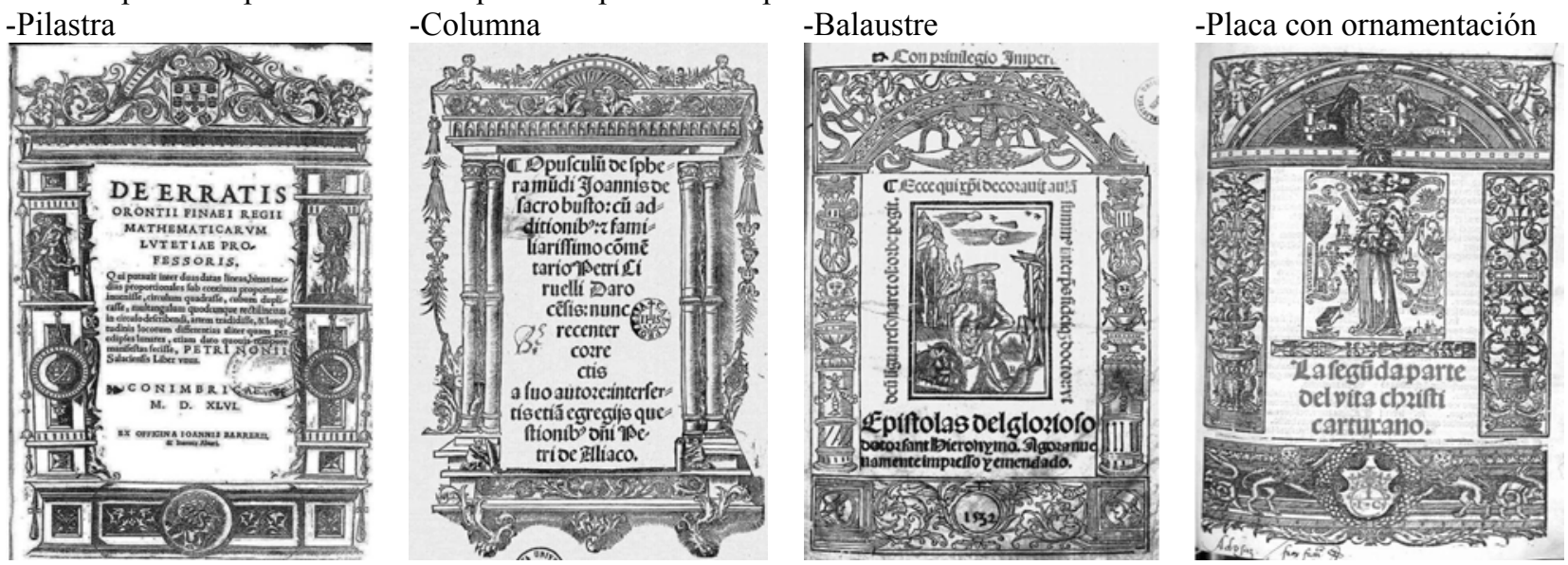
B. Tipos de elementos superiores que se emplean en las puertas:

-Frontón curvo

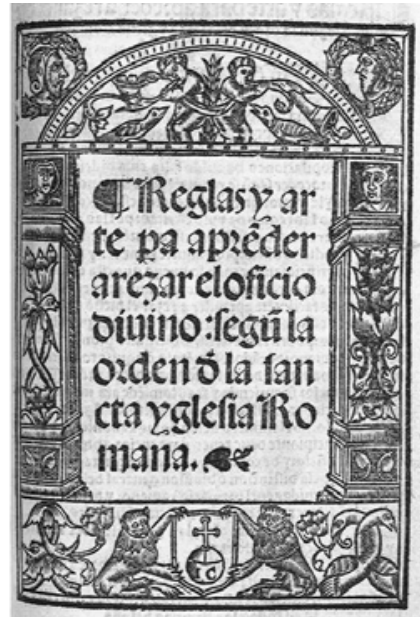

$-A r c o$

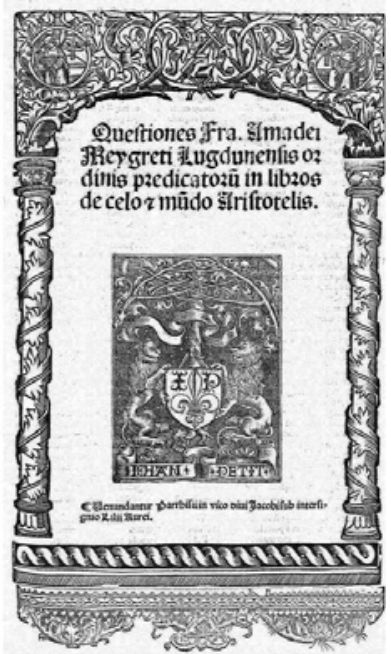

-Frontón triangular

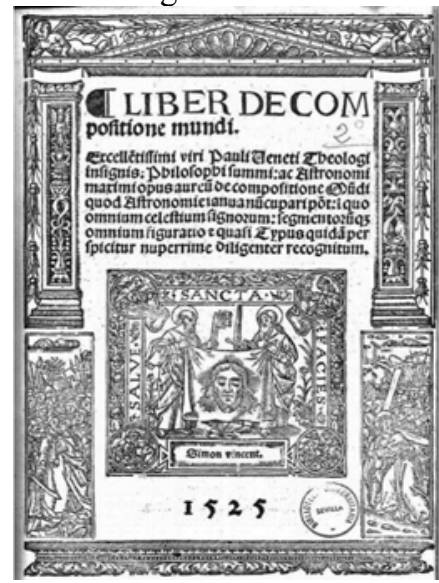

-Serliana

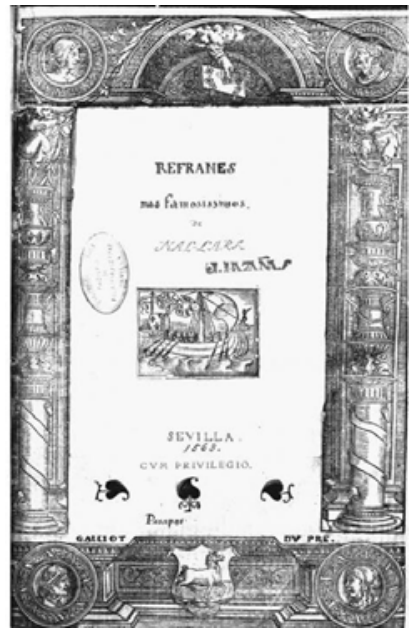

-Estructura adintelada

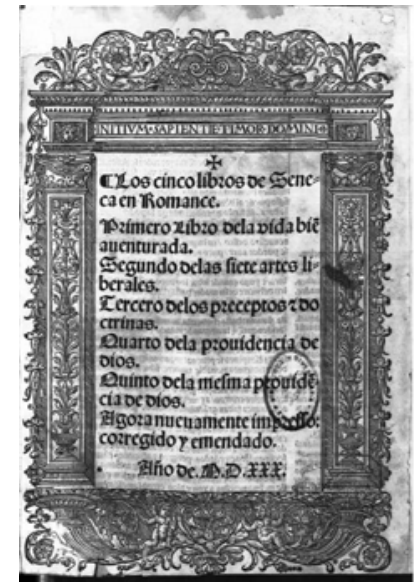

Para el análisis de los frontispicios de planchas se define un esquema que responde a la mayor variedad compositiva de los diseños de estas portadas y que incluye los siguientes elementos:

A. Tipo de técnica del grabado:
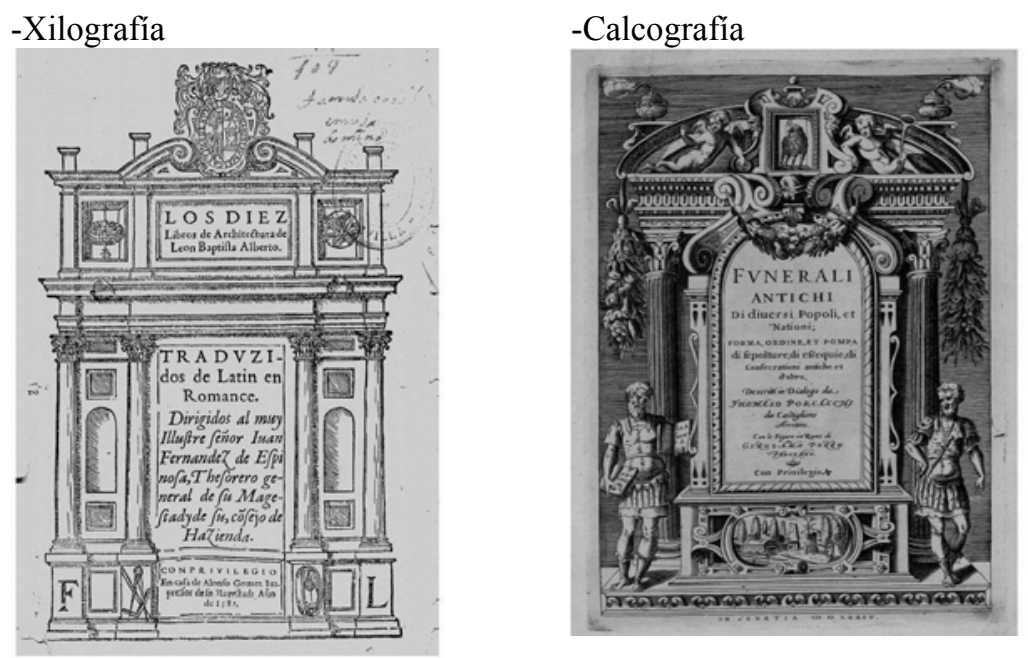
B. Tipo de estructura compositiva.

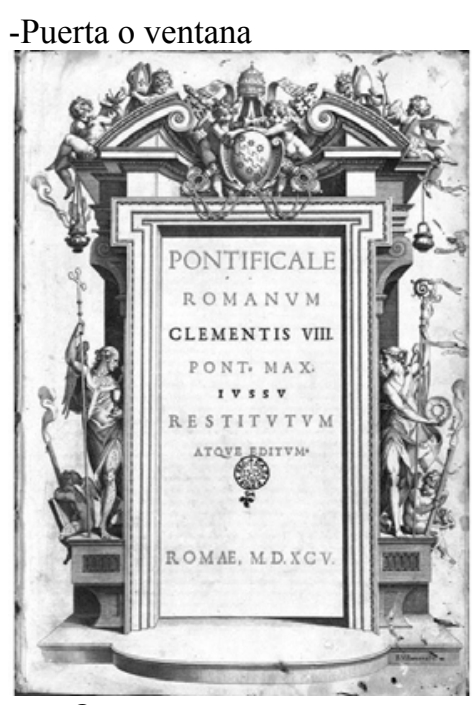

-Otros:

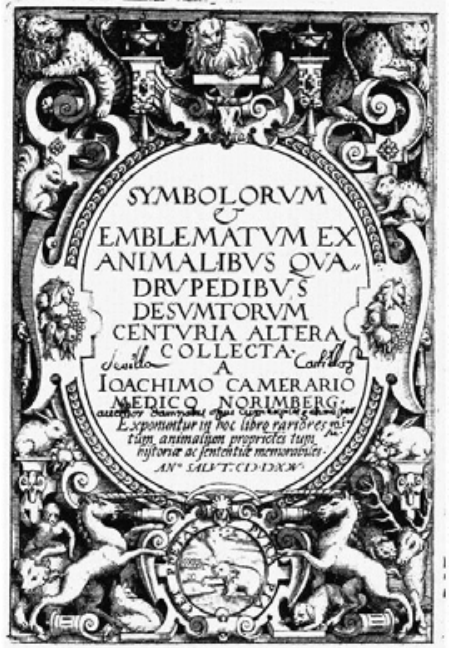

C. Tipo de iconografía:

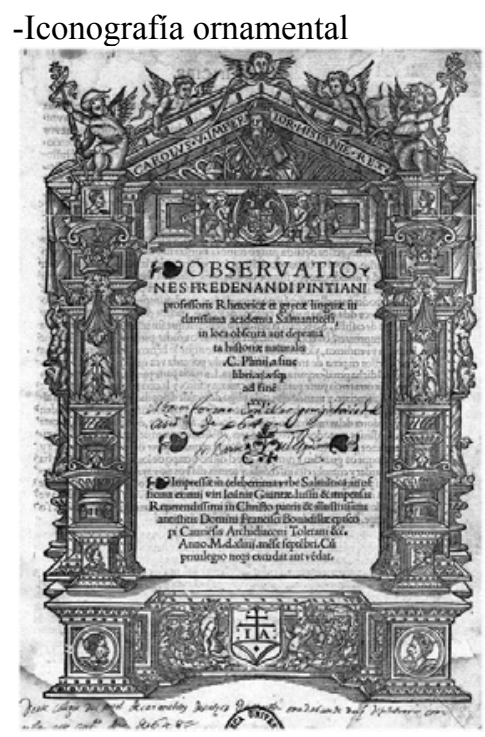

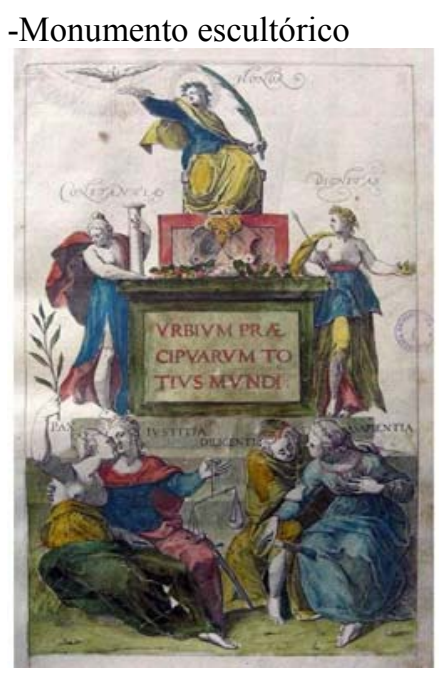
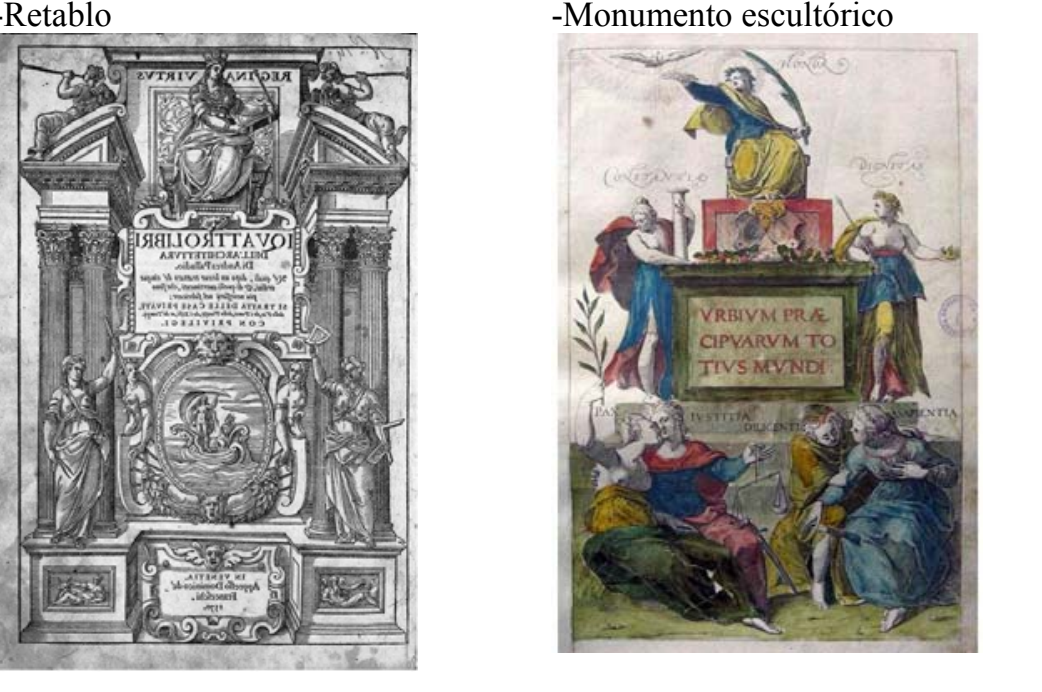
La técnica del grabado se indica porque aunque la mayoría de las portadas están realizadas con calcografía (grabado que utilizan como matriz planchas de metal), también se han identificado xilografías (grabados que utilizan como matriz tacos de madera).

La estructura compositiva se establece para diferenciar la tipología o elemento arquitectónico que responde mejor al diseño del frontispicio: puerta o ventana, retablo, monumento escultórico, otros. En este sentido hay que decir que estas tipologías arquitectónicas guardan cierta relación y a veces las diferencias son mínimas. Para establecerlos se han seguido los siguientes criterios: la puerta o ventana se considera cuando hay un predominio del vano central y la arquitectura se diseña como un complemento o marco del vano. El retablo supone la presencia de imágenes, hornacinas, basamentos o zócalos inferiores, que implican una reducción del hueco central. El monumento escultórico implica la simplificación de lo arquitectónico a formas que no tienen nada que ver con las anteriores y en favor del predominio de las figuras. La categoría otros engloba diseños que no tienen cabida en las anteriores divisiones, como grandes cartelas o tarjas manieristas.

Los comentarios de los apartados establecidos se completan con alusiones a las influencias estilísticas, a la iconografía, y a los impresores y lugares de impresión mejor representados.

\section{RESULTADOS}

De las 833 obras consultadas 84 cuentan con portadas ilustradas con frontispicios. En la Tabla I aparecen distribuidas por los tipos establecidos para el análisis.

\begin{tabular}{|c|c|c|}
\hline Frontispicios & realizados con orlas arquitectónicas & 34 portadas \\
\hline \multicolumn{3}{|c|}{ A. Tipos de soportes verticales que se emplean en las puertas } \\
\hline & Pilastra & 15 \\
\hline & Columna & 5 \\
\hline & Balaustre & 5 \\
\hline & Placa con ornamentación & 9 \\
\hline \multicolumn{3}{|c|}{ B. Tipos de elementos superiores que se emplean en las puertas } \\
\hline & Frontón curvo & 15 \\
\hline & Frontón triangular & 2 \\
\hline & Estructura adintelada & 13 \\
\hline & Arco & 2 \\
\hline & Serliana & 2 \\
\hline \multicolumn{2}{|c|}{ Frontispicios realizados con planchas } & 50 portadas \\
\hline \multicolumn{3}{|c|}{ A. Tipo de técnica del grabado } \\
\hline & Xilografía & 21 \\
\hline & Calcografía & 29 \\
\hline \multicolumn{3}{|c|}{ B. Tipo de estructura arquitectónica } \\
\hline & Puerta o ventana & 21 \\
\hline & Retablo & 15 \\
\hline & Monumento escultórico & 9 \\
\hline & Otros & 5 \\
\hline \multicolumn{3}{|c|}{ C. Tipo de iconografía } \\
\hline & Iconografía ornamental & 8 \\
\hline & Iconografía alegórica alusiva al contenido del libro & 42 \\
\hline
\end{tabular}

Tabla I: Portadas ilustradas con frontispicios.

\subsection{Los frontispicios realizados con orlas arquitectónicas}

\subsubsection{Tipos de soportes verticales que se emplean en las puertas}

Dentro de los cuatro tipos de soportes establecidos se engloban diseños muy variados:

La Pilastra puede ser plana (4-FO) o en perspectiva (18-FO, 27-FO, 30-FO), llevar capiteles o no (2-FO, 3-FO) y los capiteles pueden ser de ornamentación vegetal (16-FO, 18-FO) o cubos con caras (27-FO, 30-FO, 33-FO). Hay pilastras decoradas con "candelieri" (16-FO), con figuras a modo de cariátides (2-FO) y destaca un grupo con un diseño refinado y preciosita caracterizado por presentar un medallón en el centro con caras de perfil, que divide la 
decoración de la pilastra en dos mitades (superior e inferior) empleando motivos de candeleros o jarrones. Las pilastras se superponen a un basamento con decoración figurativa y van flanqueadas por unas guirnaldas colgantes (3FO, 15-FO, 17-FO, 22-FO, 23-FO, 24-FO), que anuncian el gusto manierista. En dos portadas (14-FO, 20-FO) los tacos de las pilastras se colocan encima de otros tacos con escenas, en un claro intento de dar mayor altura a las pilastras.

Las cinco portadas que emplean la Columna responden, en cada caso, a un modelo diferente: salomónica (26-FO), bulbosa (7-FO), con el tercio diferenciado (25-FO), de fuste liso (9-FO), doble y pareada (19-FO). Todas las columnas llevan capiteles: de estilo corintio (7-FO), corintio simplificado (9-FO, 19-FO, 26-FO) y de volutas (25-FO). Otros elementos que se emplean son: basamentos para dar más altura (7-FO, 9-FO, 25-FO); y guirnaldas, que cuelgan a los lados y sujetas a los capiteles (7-FO, 25-FO).

El Balaustre está representado en diseños variados, debido a la mayor o menor yuxtaposición de elementos y al empleo de ornamentación: superposición de tramos de fuste, angelotes, jarrones, etc. (6-FO, 11-FO), figuras agarradas al fuste (1-FO), cintas y colgantes (28-FO, 32-FO).

El modelo de Placa más usual presenta decoración de “candelieri” (13-FO, 29-FO, 34-FO) en un caso, con medallones en la mitad central (8-FO). También, existen modelos con cartelas o tarjas manieristas (FO-21), que en algunos diseños albergan figuras a modo de hornacinas (5-FO, 10-FO). En una portada las placas o pilastras se sustituyen por una superposición de bustos alojados en hornacinas (31-FO).

\subsubsection{Tipos de elementos superiores que se emplean en las puertas}

De los elementos superiores de las puertas el más reiterado es el Frontón curvo. Se constatan dos modelos: sin perspectiva y con perspectiva.

Dentro de los frontones curvos sin perspectiva se dan estas variantes:

-Arco con extradós formado por una moldura decorada con una greca y el tímpano con motivos ornamentales sobre fondo blanco (27-FO, 30-FO, 32-FO) o una escena (22-FO).

-Arco con extradós formado por una moldura lisa y el tímpano con un escudo heráldico (5-FO).

-Arco con inscripción en el extradós y una escena en el tímpano (7-FO).

En los frontones curvos con perspectiva se presentan estos modelos:

-Frontón con hornacina que alberga un escudo (5-FO) o en forma de venera con gallones (31-FO).

-Arco con extradós formado por una moldura decorada con motivo de cinta liada y el efecto de profundidad conseguido con rayado. El tímpano presenta un escudo (8-FO, 12-FO, 13-FO, 29-FO, 33-FO, 34-FO).

-Arco con extradós de moldura decorada con motivos vegetales, el efecto de profundidad se consigue con rayado. El tímpano se resuelve con motivos ornamentales sobre fondo en blanco (6-FO).

-Arco con inscripción en el extradós y casetones en el intradós. En el tímpano se coloca un escudo (18-FO).

Las portadas con Frontón triangular coinciden en que el frontón es estrecho y alargado, y el tímpano va decorado con gallones (14-FO, 20-FO).

Los frontispicios resueltos con una Estructura adintelada ocupan el segundo lugar y presentan estas alternativas:

-Taco rectangular con decoración ornamental plateresca (28-FO).

-Entablamento: friso de ovas y cornisa con decoración plateresca (19-FO); friso con inscripción y cornisa clásica y todo coronado por una crestería plateresca (16-FO), friso con inscripción (9-FO), friso sencillo y coronado por crestería plateresca (4-FO), friso con decoración plateresca y coronado por una hornacina de medio punto (2-FO).

-Taco con medallón central flanqueado por ornamentación plateresca dispuesta de forma simétrica a ambos lados (3-FO, 15-FO, 17-FO, 23-FO, 24-FO).

-Escena figurada sobre un fondo de cartelas y sobre un reducido entablamento (10-FO).

-Taco que reproduce una cartela con una escena en el centro (21-FO).

Los dos portadas que emplean el Arco coinciden en que el arco es de tipo rebajado, pero un arco está formado por una trama vegetal con dos medallones en las enjutas (26-FO) y otro, por una moldura de acantos que configura la rosca del arco, con dos angelotes recostados en los lados, sosteniendo una guirnalda que cuelga por el centro del arco (1-FO).

Las dos portadas con Serliana responden a modelos distintos: en una portada (11-FO), una fina cornisa se interrumpe en el centro para abrir un arco con el extradós formado por una moldura de hojas de laurel y el intradós por 
casetones que acentúan la perspectiva. Dentro del arco se sitúa un motivo alegórico en el que una mano sale de una nube y sostiene un libro. Encima de la cornisa y a los dos lados del arco, se sitúan dos medallones.

En la otra portada (25-FO), el diseño no responde propiamente a una serliana, pues el fino entablamento (formado por un friso en el que alternan formas ovaladas y circulares y una cornisa) no se interrumpe en la parte central por el arco, sino que éste se apoya sobre el entablamento. El arco es reducido y alberga en su interior un santo mitrado. A ambos lados del arco, y sentados sobre la cornisa, se sitúan ángeles tocando trompetas.

Toda la ornamentación de estas portadas reproduce el universo de la ornamentación plateresca y guardan estrecha relación con las portadas de los edificios del momento, que según Bermejo (1945, p. 269) eran de diversos tipos:

"Uno [de los tipos] es el arco, de medio punto o apuntado, con grandes dovelas, que se usa en palacios del siglo XII, góticos, y en muchos del Renacimiento ya avanzados. No responde, pues, a estilo ni época determinado. El otro es el vano adintelado con columnas laterales, entablamento y, a veces, frontón. Ese frontón no siempre se presenta en su forma triangular corriente, sino que con frecuencia se incurva, describiendo un semicírculo o, simplemente, un arco de círculo”.

En las 34 portadas analizadas también está presente la iconografía: imagen del autor (6-FO: taco central de la portada con San Jerónimo penitente); composiciones referidas al contenido del libro (32-FO: artes liberales; 12-FO, 13-FO, 33-FO y 34-FO: vida de Cristo de la célebre obra Vita Christe del Cartujano); marca del impresor (25-FO: Iacobum Giunta, 14-FO: Simón Vincentius, 17-FO: Ascensio \& Ioanne Paruo); monogramas de órdenes religiosas (7FO: dominicos); escudos heráldicos (2-FO: Duque de Arcos).

Respecto a los lugares de impresión están presentes 4 países (España, Italia, Francia y Portugal) y 12 ciudades (Sevilla, Granada, Salamanca, Alcalá de Henares, Estrasburgo, Lyon, París, Coimbra, Nápoles, Roma y Venecia). Las ciudades mejor representadas son Sevilla (12 obras), París ( 7 obras) y Lyon (4 obras). Se refleja cómo Sevilla fue uno de los centros impulsores de la ilustración en España. Se suele admitir que el Fasciculus temporum (Sevilla, 1480, por Bartolomé Segura y Alfonso del Puerto) fue el primer libro ilustrado del que se conservan ejemplares (Merino, 2009, p. 84).

Entre los impresores activos en España destaca en Sevilla Jacobo Cromberger ( 7 obras), que es el padre de una dinastía de impresores que se establece en Sevilla por su importancia comercial, económica y religiosa y que va a dominar en el terreno de la impresión de libros, pues durante el periodo que está activo (1504-1528) "alrededor de dos tercios de los libros impresos en Sevilla salieron de su imprenta" (Martínez, 2003, p. 1). También trabaja en Sevilla Juan de León (2 obras), conocido por su papel como fundidor de tipos (Cátedra y López Vidriero, 2002, p. 75). De Alcalá de Henares está representado Miguel de Eguía (2 obras), suegro de Brocar e introductor de la imprenta en Navarra, fue uno de los mayores editores de su época. De otros países está Antoine du Ry con taller en Lyon ( 2 obras).

\subsection{Los frontispicios realizados con planchas}

\subsubsection{Tipo de técnica del grabado}

La técnica de grabado propia de los frontispicios es la calcografía, más eficaz para componer toda la portada en una sola plancha incluida la parte textual. Esta técnica se ha empleado en 29 de las portadas recopiladas. Sin embargo, la xilografía también se ha utilizado, como se comprueba en las 21 portadas restantes.

Las diferencias son claras, pues la xilografía produce unos diseños más planos, con menos volumen, debido a la dificultad de plasmar las graduaciones entre el blanco y el negro (23-FP, 33-FP, 35-FP). El éxito de la calcografía, entre otros aspectos, se debe a la superación de estos límites, permitiendo composiciones de efectos más pictóricos gracias a que la talla de la plancha con el buril permite, mediante finas incisiones, conseguir los grises que ayudan a producir el efecto de volumen deseado (28-FP, 36-FP, 42-FP).

\subsubsection{Tipo de estructura arquitectónica}

Los frontispicios que emplean la Puerta o ventana reflejan las influencias de los diseños arquitectónicos del momento: motivos platerescos (2-FP, 8-FP, 23-FP, 24-FP, 34-FP), influencias de Serlio ${ }^{4}$ (9-FP, 22-FP, 26-FP) o del clasicismo de Alberti (33-FP). En algunos se aprecia el protagonismo de elementos arquitectónicos singulares como los almohadillados de tipo militar toscano (35-FP, 45-FP), las cariátides (39-FP), los áticos rematados con bolas del tipo escurialense (22-FP, 38-FP, 46-FP), las figuras recostadas en los lados del frontón (32-FP), el orden gigante (26$\mathrm{FP}, 38-\mathrm{FP})$ o las estructuras en perspectiva (38-FP). 
También abundan diseños manieristas que anuncian el barroco (14-FP, 28-FP, 29-FP 32-FP, 37-FP).

En los modelos que utilizan el Retablo, la estructura esencial responde a un cuadro de texto central entre dos figuras sobre peanas del banco y rematado por un frontón (17-FP, 18-FP, 19-FP, 36-FP). También están presentes los rasgos del retablo romanista: frontones triangulares (7-FP), curvos (30-FP), así como la presencia de figuras alegóricas, ángeles o puttis sobre las volutas (36-FP, 40-FP). El romanismo destaca en España en el último tercio del siglo XVI, bajo la influencia de Juni (Castañer, 1994, p. 222).

Por lo demás, el influjo de la arquitectura del momento es semejante al que se detecta en los diseños de puertas o ventanas: destacan los diseños manieristas (12-FP, 17-FP, 30-FP, 40-FP), en concreto con influjos de Serlio (7-FP, 19FP); están presentes también las soluciones en perspectiva (7-FP, 17-FP, 18-FP) o con cariátides (7-FP, 25-FP). En varios frontispicios se utilizan los soportes laterales con nichos (13-FP, 41-FP) o con figuras delante, a modo de esculturas (10-FP, 18-FP, 19-FP).

Dentro de la categoría Monumento escultórico se pueden destacar, por responder a diseños que recuerdan a los monumentos urbanos, los siguientes: diseño de un gran pedestal que sirve de soporte a tres figuras alegóricas (religión, Cibeles, política), en el frontal del pedestal se dispone una cartela con los datos del libro y en la parte inferior otras figuras alegóricas como Penates o Lares (4-FP); diseño en el que el título de la obra aparece en un gran pedestal sobre una escalinata que es el centro de la composición, completada con grandes figuras alegóricas: honor (sobre el pedestal), constancia, dignidad, paz, justicia, diligencia y sabiduría (50-FO); diseño en el que la portada la ocupa una compleja solución que recuerda un monumento funerario: sobre una estructura con hornacinas que albergan figuras alegóricas (caridad, religión, etc.), se dispone una especie de ataúd del que sale un esqueleto animado en conversación con una figura en actitud orante (20-FO).

El apartado Otros incluye cuatro diseños a modo de complejos marcos de ornamentación manierista (5-FP, 27-FP, 43-FP, 44-FP) y una composición que recuerda una fuente ornamental dispuesta ante una gran hornacina flanqueada por atlantes (3-FO).

\subsubsection{Tipo de iconografía}

Respecto a la iconografía se pueden establecer dos grupos: uno formado por las portadas que emplean una iconografía meramente ornamental, que sólo está presente en 8 portadas (3-FP, 5-FP, 8-FP, 27-FP, 29-FP, 34-FP, 39FP, 45-FP); el segundo grupo lo forman el resto de las portadas (42 portadas), que utilizan una iconografía alusiva al contenido del libro. En este grupo las alegorías suelen estar representadas por figuras que hacen referencia a conceptos como las virtudes (42-FO: fe, caridad y esperanza) o son figuras que portan atributos representativos del concepto (4FP: religión y política; 17-FP: arquitectura; 50-FP: sabiduría, justicia, constancia, etc.); también pueden aludir a los personajes tratados en la obra (48-FP: Cleopatra, Dionisios, etc.) o incluso al nombre del impresor (29-FP).

Estos elementos figurativos es frecuente colocarlos como parte del diseño arquitectónico, normalmente a ambos lados del vano central, sobre pedestales o sobre el basamento y delante de pilastras o columnas (10-FP, 12-FP, 18-FP). Lo cual hace que los elementos arquitectónicos desempeñen una función activa:

“al ser sustentantes y portadores de los diversos elementos iconográficos que conforman el conjunto total de la portada [...] servirán de telón de fondo para las figuras principales de los frontispicios” (Cacheda, 2006, p. 233).

También, es importante destacar que esta relación de la ilustración de la portada con el contenido del libro va a suponer el fin de una práctica frecuente hasta el momento: reutilizar las ilustraciones de unos libros a otros. Cuando las ilustraciones de los libros eran meramente ornamentales era posible emplearlas en libros diferentes, de tal modo que los tacos xilográficos se pasaban de unos impresores a otros (García Olmedo, 1997, p. 80-81). Esto no es posible cuando las ilustraciones están vinculadas al contenido del texto.

Respecto a los lugares de impresión de los libros que utilizan frontispicios con planchas, se diferencian 3 países (España, Italia y Alemania) y 5 ciudades (Madrid, Venecia, Roma, Colonia, Frankfurt). De las ciudades destacan Venecia (12 obras) y Roma (6 obras), datos que corroboran que Italia fue el segundo país de Europa donde entró la imprenta y Venecia fue la ciudad donde más se desarrolló (Fernández, 2015, p. 1). Le siguen otras ciudades como Frankfurt am Main (4 obras), Madrid (4 obras) y Colonia (4 obras). Los impresores mejor representados son los venecianos Simón Galignani de Karera (3 obras) y Girolamo Franceschi Sanese (3 obras). 


\section{CONCLUSIONES}

La bibliografía existente insiste en que los frontispicios se consideran una manifestación de las portadas realizadas con planchas calcográficas, principalmente durante el siglo XVII. Sin embargo, los resultados de este trabajo reflejan por un lado, que los frontispicios son frecuentes ya en el siglo XVI; y por otro lado, que hay modelos realizados con tacos xilográficos que se pueden considerar claros precedentes. En este estudio se han denominado "frontispicios con orlas arquitectónicas”.

La gran variedad de detalles que diferencian a los diseños de los frontispicios localizados ha hecho aconsejable realizar un esquema para clasificarlos y facilitar su análisis. El esquema elaborado se aporta en este trabajo como una propuesta para otros trabajos semejantes.

En los frontispicios analizados se evidencia la influencia de la arquitectura del momento, sobre todo, de la traza de puertas y retablos. De tal modo, que el conjunto de portadas grabadas que han llegado a nuestros días se puede considerar un buen repertorio de diseños y esquemas arquitectónicos para estudiar una manifestación de la arquitectura de la época.

En algunas portadas realizadas con frontispicios de planchas calcográficas los diseños se apartan de los esquemas arquitectónicos y se basan en el predominio de las figuras, es decir lo arquitectónico, aunque presente, se reduce y en algunos casos desaparece. En este estudio se propone identificarlos bajo la denominación "Monumentos escultóricos".

Las tendencias estilísticas mejor reflejadas en los frontispicios analizados responden al estilo plateresco en el caso de los frontispicios de orlas arquitectónicas; y al manierismo italiano tardío o al modelo herreriano español, en el caso de los frontispicios con planchas, dando lugar a unos diseños de transición entre el manierismo y el barroco.

Los elementos figurativos e iconográficos tienen mayor presencia en los frontispicios de planchas que en los de orlas arquitectónicas. En éstos, cuando están presentes lo hacen como un elemento ornamental, mientras que en los primeros alcanzan un mayor protagonismo formando parte de una iconografía en relación con el asunto del libro en cuestión.

La importancia del fondo antiguo de la Biblioteca de la Universidad de Sevilla se refleja en muchos aspectos, uno de ellos es la variada representación de impresores y de lugares de impresión que están presentes en la selección de obras estudiadas en este trabajo.

\section{NOTAS}

\footnotetext{
${ }^{1}$ Los datos sobre la constitución del fondo antiguo de la Universidad de Sevilla se han obtenido del apartado "Fondos" de la web de la Biblioteca: $<$ http://bib.us.es/bibliotecas_y_horarios/machado/fondo_antiguo/fondos $>$ y de Caracuel Moyano, Rocío. El fondo histórico de la Biblioteca Universitaria de Sevilla. En: Caracuel Moyano, Rocío; Llordén Miñambres, Moisés (eds.). El libro antiguo en las bibliotecas españolas. Oviedo: Universidad de Oviedo, Servicio de Publicaciones, 1998, p. 183-199.

${ }^{2}$ Citado por: Zulueta Pérez, Patricia; Olcese Segarra, Mariano. Las técnicas de grabado y la litografía en los libros de máquinas de los siglos XV al XIX. STVDIVM. Revista de Humanidades, 2012, vol. 18, p. 61-97.

${ }^{3}$ Este autor incluye un breve estado de la cuestión sobre trabajos de estas características.

${ }^{4}$ Por ejemplo se reflejan elementos de los diseños recogidos en su obra: Libro estraordinario di Sebastiano Serlio bolognese, nel quale si dimostrano trenta porte di opera rustica mista con diuersi ordini \& uenti di opera dilicata di diuerse specie con la scrittura dauanti, che narra il tutto. In Venetia: Appresso Francesco Senese, \& Zuane Krugher Alemano compagni, 1566.
}

\section{BIBLIOGRAFÍA}

BERMEJO, E. Portadas toledanas con frontispicio de vuelta redonda. Archivo español de Arte, 1945, vol. 18, n $71, \mathrm{p}$. 266-276. Disponible en: <http://digital.csic.es/bitstream/10261/26844/1/Portadas_toledanas.pdf $>$ [Consulta: 1 de mayo de 2015].

CABO DE LA SIERRA, G. Grabados, litografías y serigrafías, técnicas y procedimientos. Valladolid: Colegio Oficial de Aparejadores y Arquitectos Técnicos de Valladolid / Esti-Arte, 1981.

CACHEDA BARREIRO, M. La portada del libro en la España de los Austrias menores. Un estudio iconográfico. Tesis doctoral. Santiago de Compostela: Universidad de Santiago de Compostela, 2006. Disponible en: $<$ http://dspace.usc.es/handle/10347/9510> [Consulta: 8 de mayo de 2015]. 
CARACUEL MOYANO, R. El fondo histórico de la Biblioteca Universitaria de Sevilla. En: CARACUEL MOYANO, R.; LLORDÉN MIÑAMBRES, M. (eds.). El libro antiguo en las bibliotecas españolas. Oviedo: Universidad de Oviedo, Servicio de Publicaciones, 1998, p. 183-199.

CASTAÑER LÓPEZ, X. El funcionamiento de la imagen en el retablo alavés de 1500. En: Los clasicismos en el arte español: actas del X Congreso del CEHA. Madrid: UNED, 1994, p. 219-226.

CÁTEDRA, P.M. y LÓPEZ-VIDRIERO, M.L. (dirs.). De libros, librerías, imprentas y lectores. Salamanca: ediciones de la Universidad de Salamanca, Seminario de Estudios Medievales y Renacentistas, 2002.

CIVIL, P. El frontispicio y su declaración en algunos libros del Siglo de Oro español. En: ARREDONDO SIRODEY, S.; CIVIL, P. y MONER, M. (coords.). Paratextos en la literatura española (siglos XV-XVIII). Madrid: Casa de Velázquez, 2009, p. 501-540.

CORNEJO-VEGA, F.J. La propaganda en las portadas de libros de la orden de San Basilio en España (siglo XVII). Cuadernos de arte e iconografía, 2008, vol. 17, $\mathrm{n}^{\mathrm{o}}$ 34, p. 495-534. Disponible en: $<$ http://www.fuesp.com/pdfs_revistas/cai/numeros\%20completos/cai-34.pdf $>$ [Consulta: 1 de mayo de 2015].

FERNÁNDEZ, M.A. Invención, difusión y desarrollo de la imprenta en los siglos XVI y XVII. Historia Viva, 2015. Disponible en: <http://www.islabahia.com/arenaycal/2010/170_abril/miguel_a_fernandez170.asp > [Consulta: 7 de mayo de 2015].

GARCÍA OLMEDO, M. La Ilustración en la estructura interna del libro. Libros ilustrados del siglo XVII en la Biblioteca Menéndez Pelayo. SIGNO. Revista de Historia de la Cultura Escrita, 1997, vol. 4, p. 79-95.

MARTÍN ABAD, J. Los libros impresos antiguos. Valladolid: Universidad de Valladolid, Secretariado de Publicaciones e Intercambio, 2004.

MARTÍNEZ, L. Los Cromberger: una imprenta de Sevilla y Nueva España. Archivo de Tiempo y Escritura, 2003. Disponible en: <http://www.azc.uam.mx/publicaciones/tye/loscrombergerunaimprentadesevilla.htm> [Consulta: 8 de mayo de 2015].

MERINO PERAL, E. La ilustración de los Tratados de Arte Militar, impresos y conservados en la Biblioteca Nacional, 1500-1671. Algunas consideraciones sobre autores de los textos, de los grabados e imprentas especializadas y coleccionistas. Anales de Historia del Arte, 2009, vol. 19, p. 77-116.

MUÑOZ JIMÉNEZ, J.M. El manierismo en la arquitectura española de los siglos XVI y XVII: la fase clasicista (1560-1630). Cuadernos de arte e iconografía, 1992, vol. 5, $\mathrm{n}^{\mathrm{o}}$ 9. Disponible en: $<$ http://www.fuesp.com/pdfs_revistas/cai/9/cai-9-2.pdf $>$ [Consulta: 17 de abril de 2015].

REYES GÓMEZ, F. de los. Estructura formal del libro antiguo. En: PEDRAZA GRACIA, M.J.; CLEMENTE SAN ROMÁN, Y. y REYES GÓMEZ, F. de los. El libro antiguo. Madrid: Editorial Síntesis, 2003, p. $207-247$.

RODRÍGUEZ PELAZ, C. El grabado barroco en los impresos vasco-navarros. Ondare. Cuadernos de Artes Plásticas y Monumentales, 2000, vol. 19, p. 151-182.

ZULUETA PÉREZ, P. y OLCESE SEGARRA, M. Las técnicas de grabado y la litografía en los libros de máquinas de los siglos XV al XIX. STVDIVM. Revista de Humanidades, 2012, vol. 18, p. 61-97. 
Apéndice 1: Imágenes de las portadas

I. Frontispicios con orlas arquitectónicas

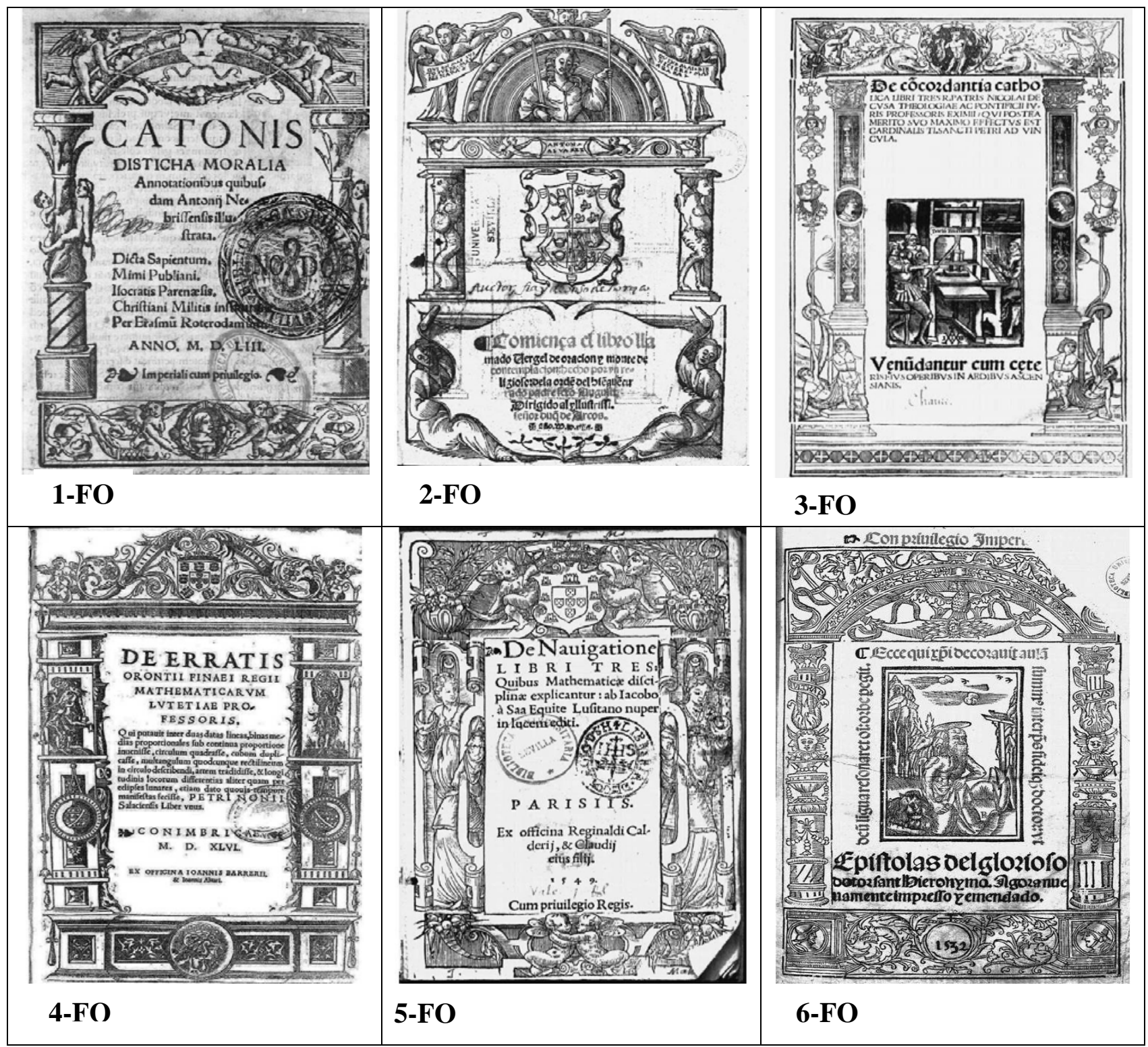




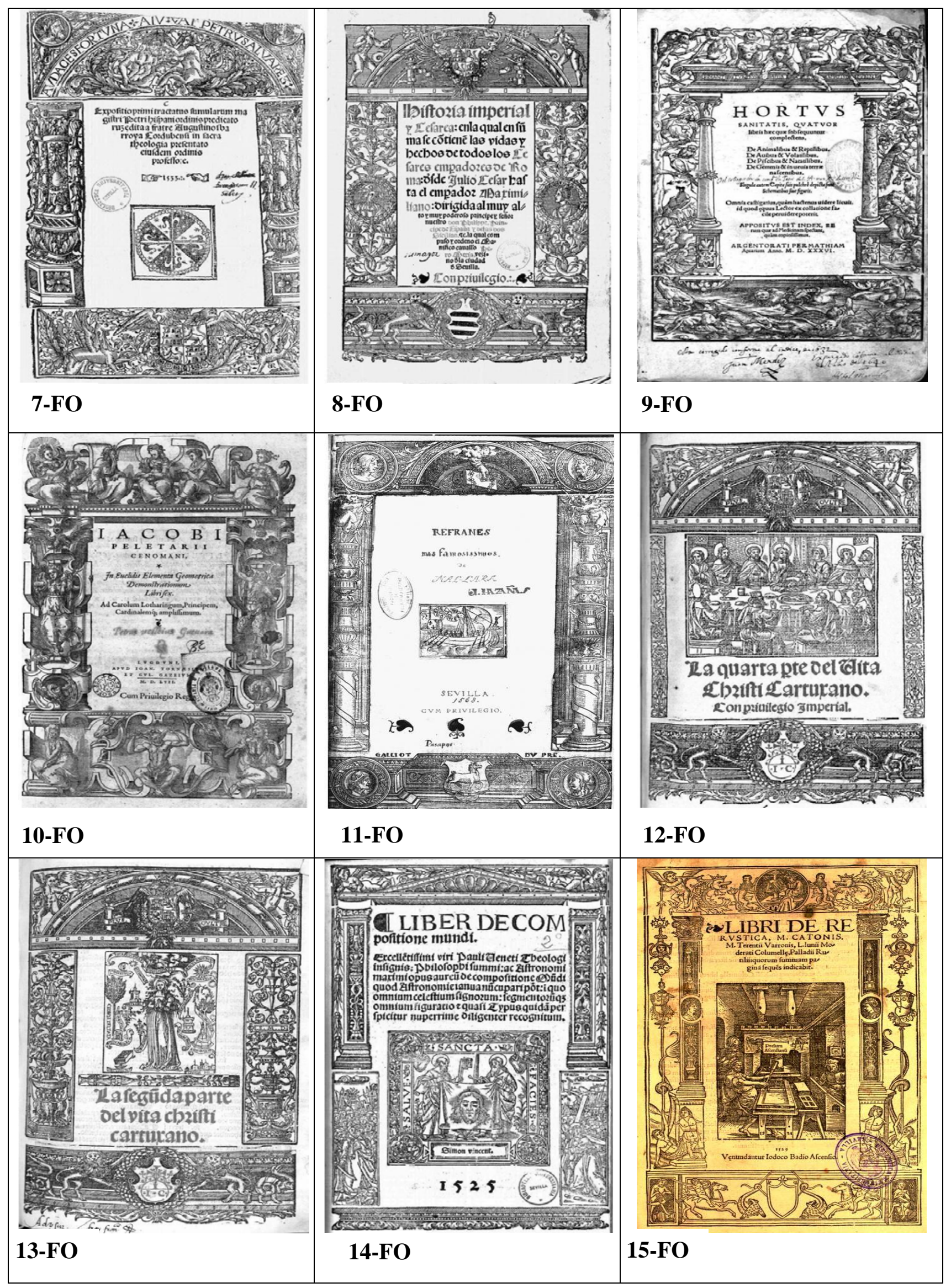




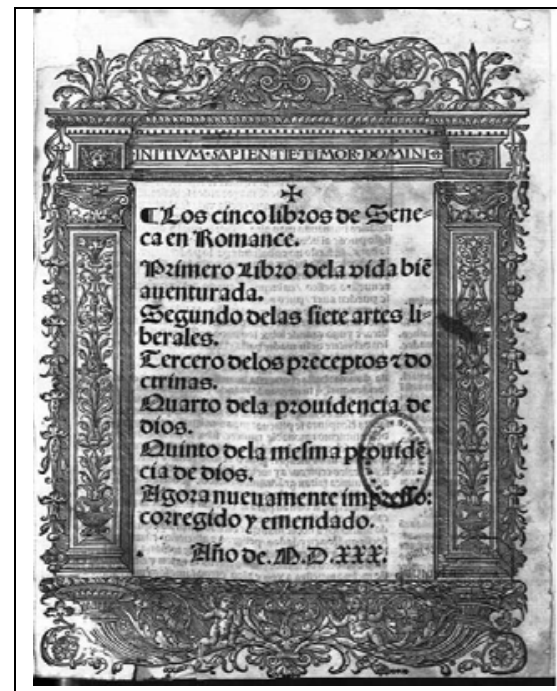

\section{6-FO}

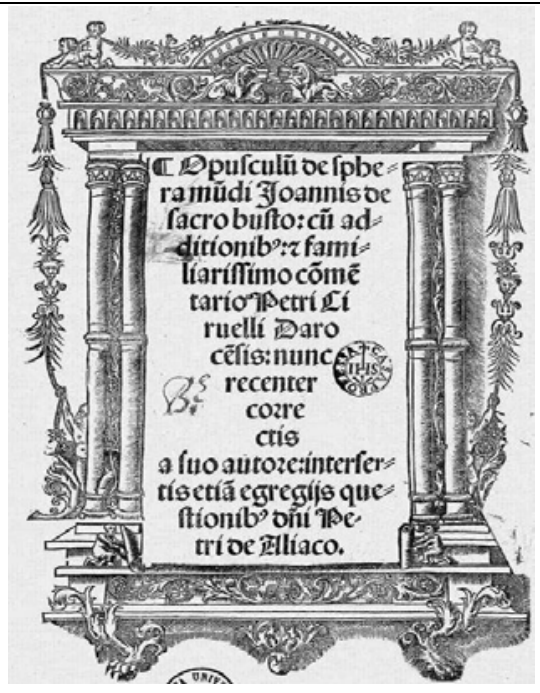

19-FO

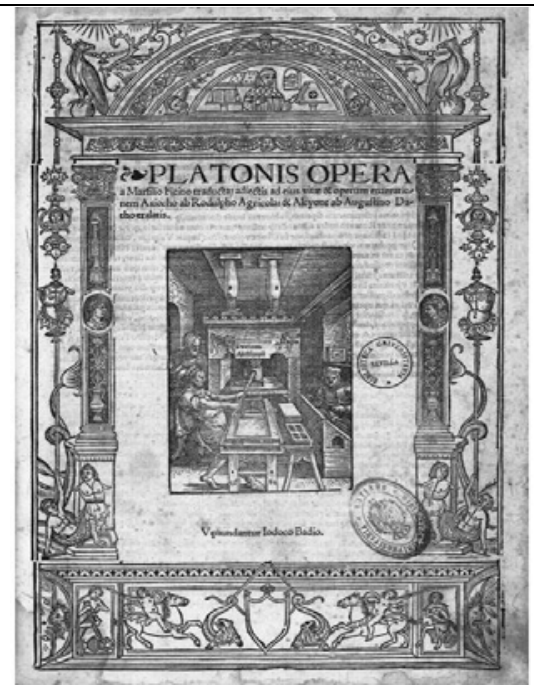

22-FO

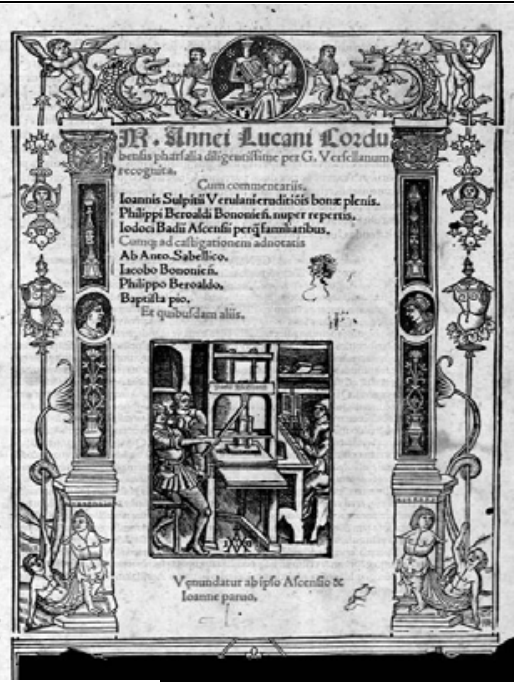

\section{7-FO}

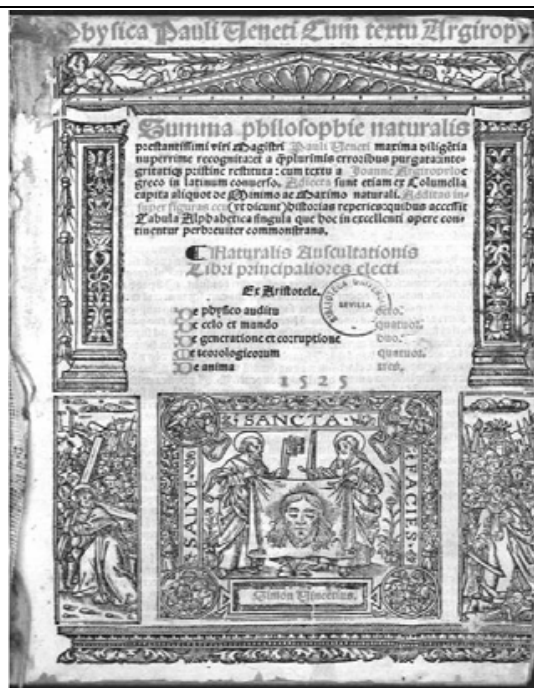

20-FO

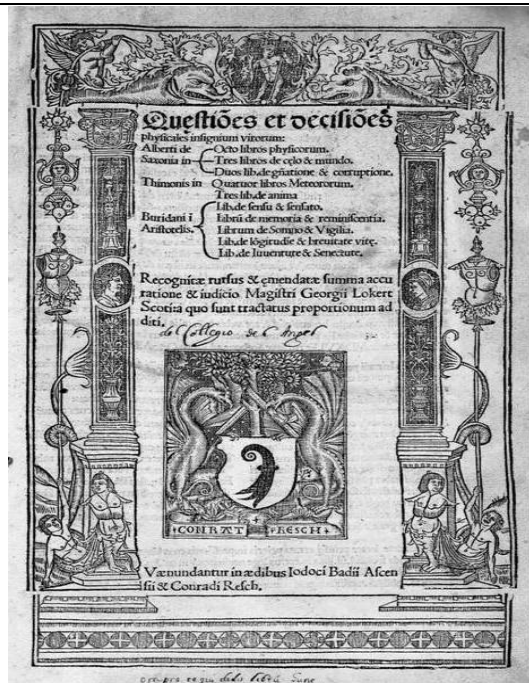

23-FO

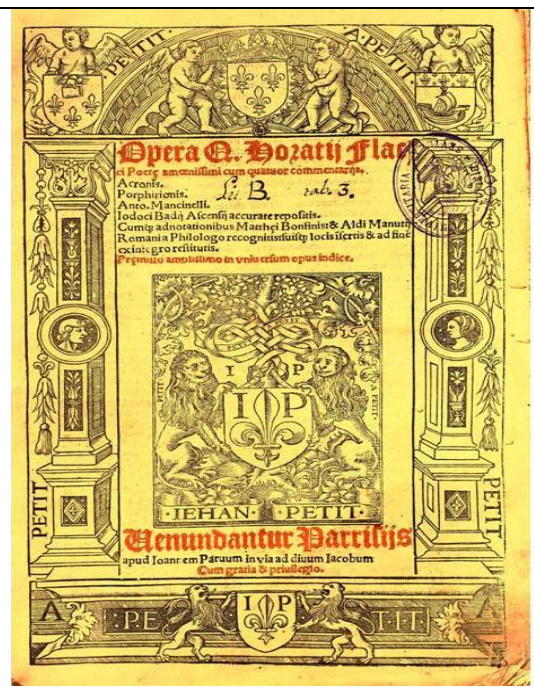

18-FO

15 Numes?

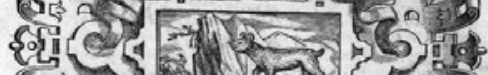

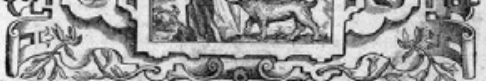
(P) PHYTOGNOMONICA (C) I 10.BAPTISTAE If: IO

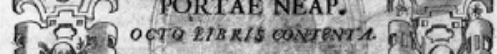
6. 2.

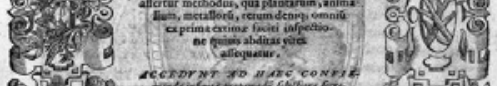
130

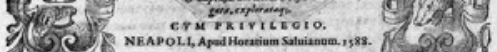

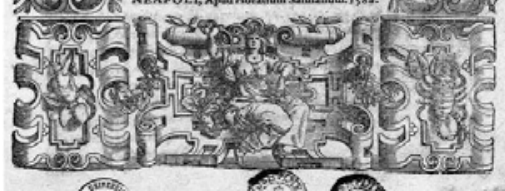
21-FO

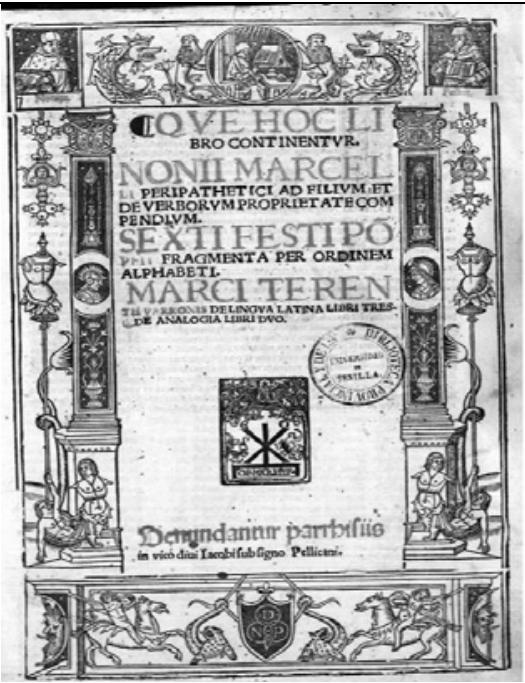

24-FO 


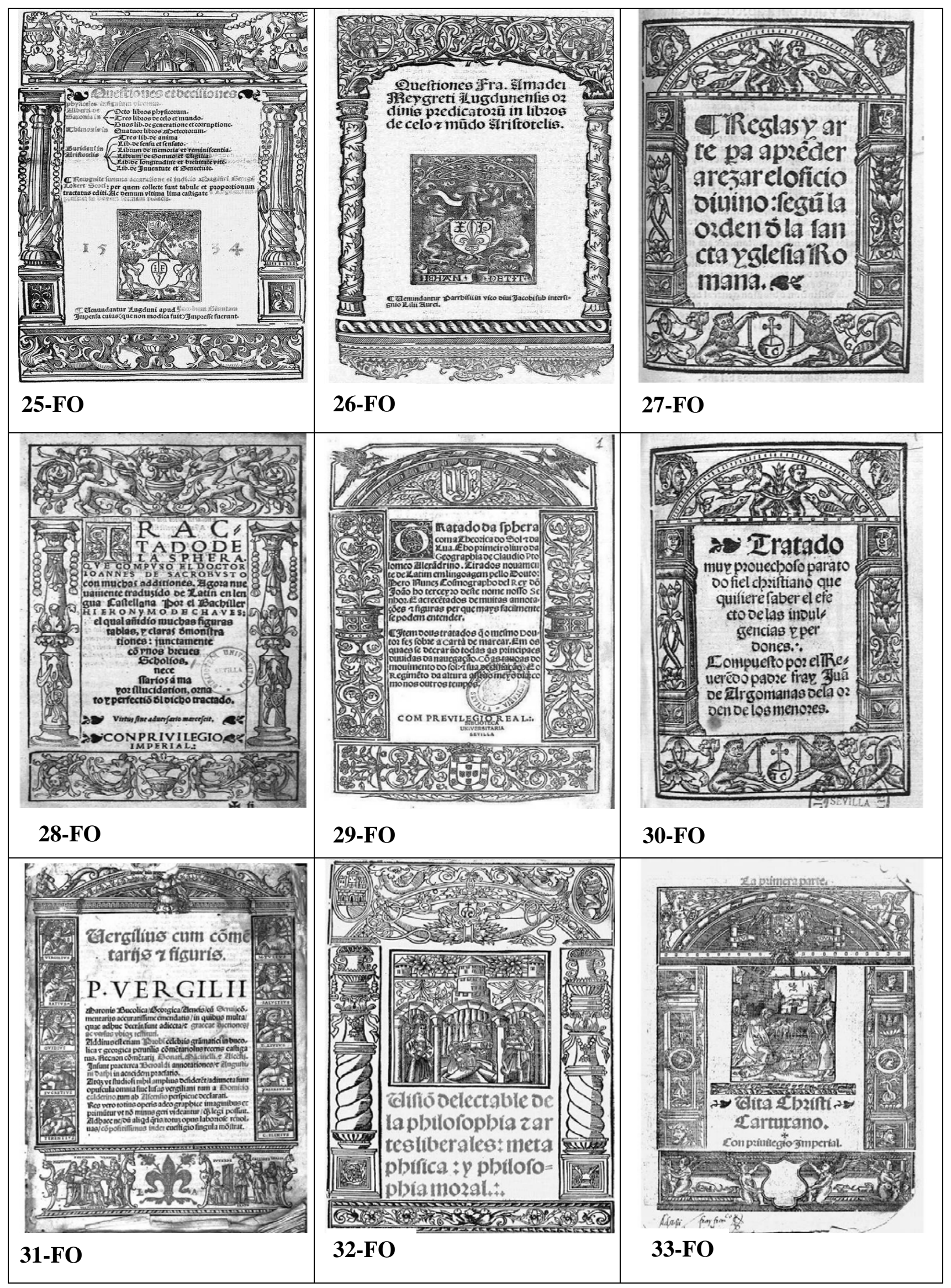




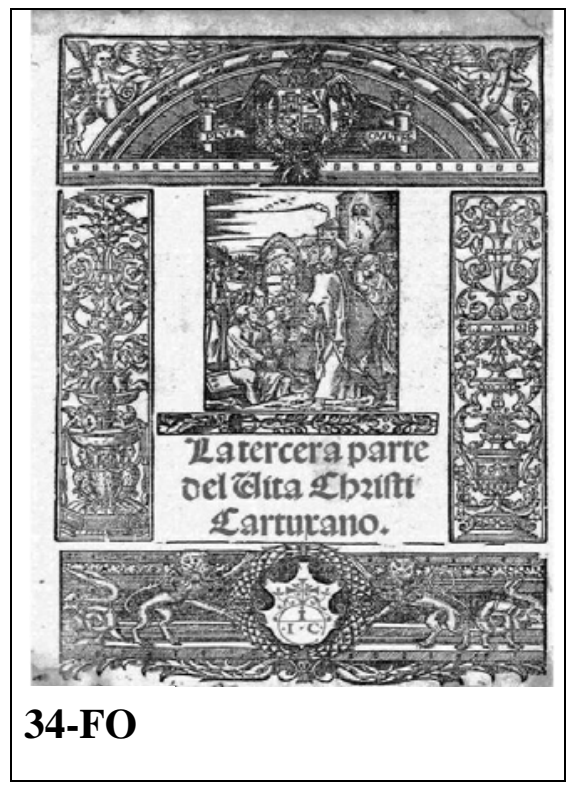

II. Frontispicios con planchas calcográficas

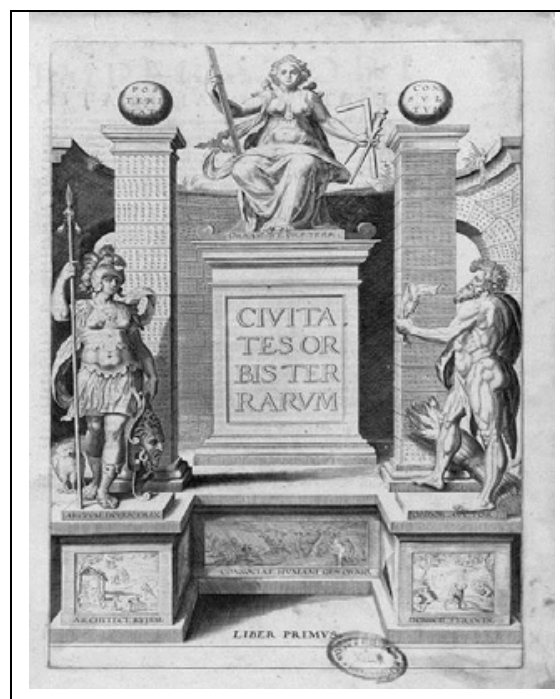

1-FP

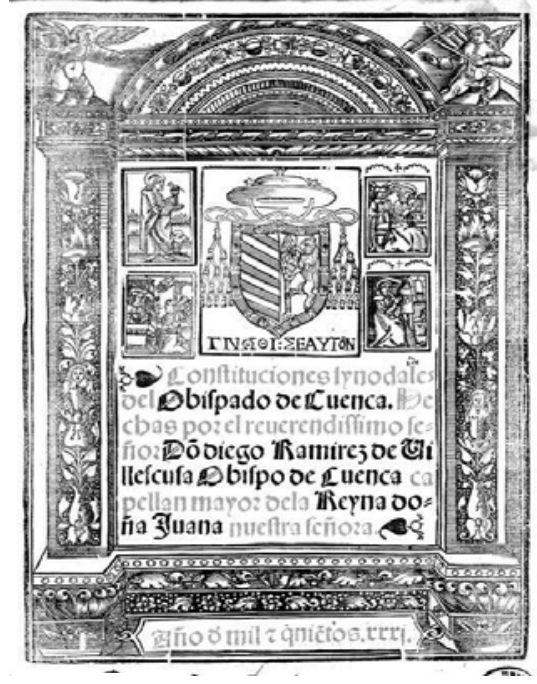

2-FP

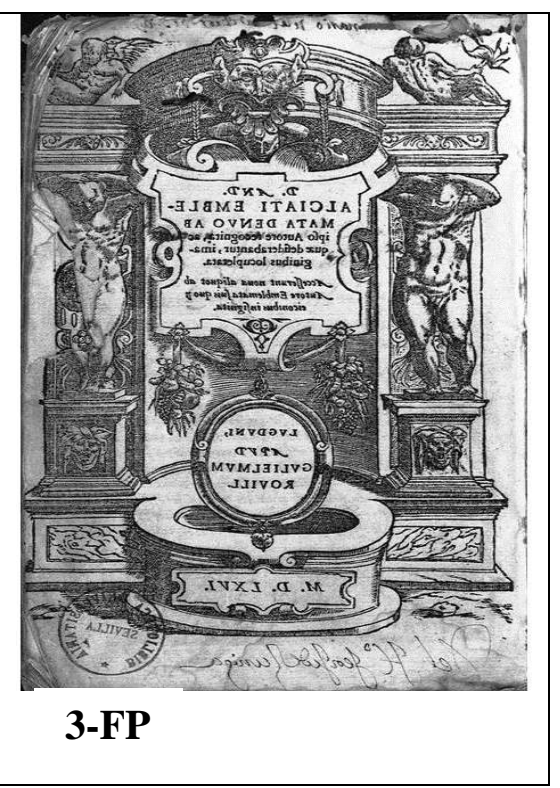




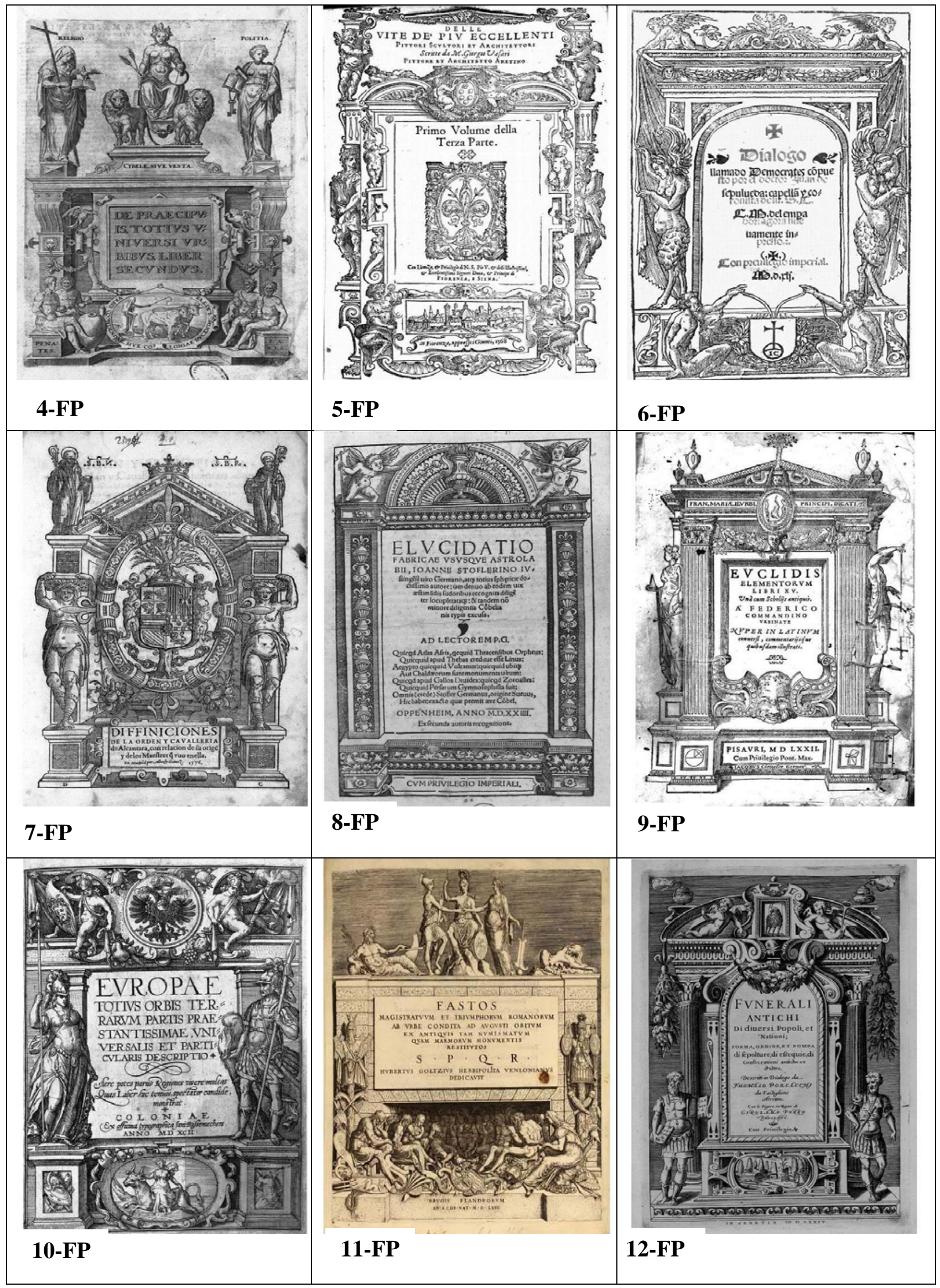




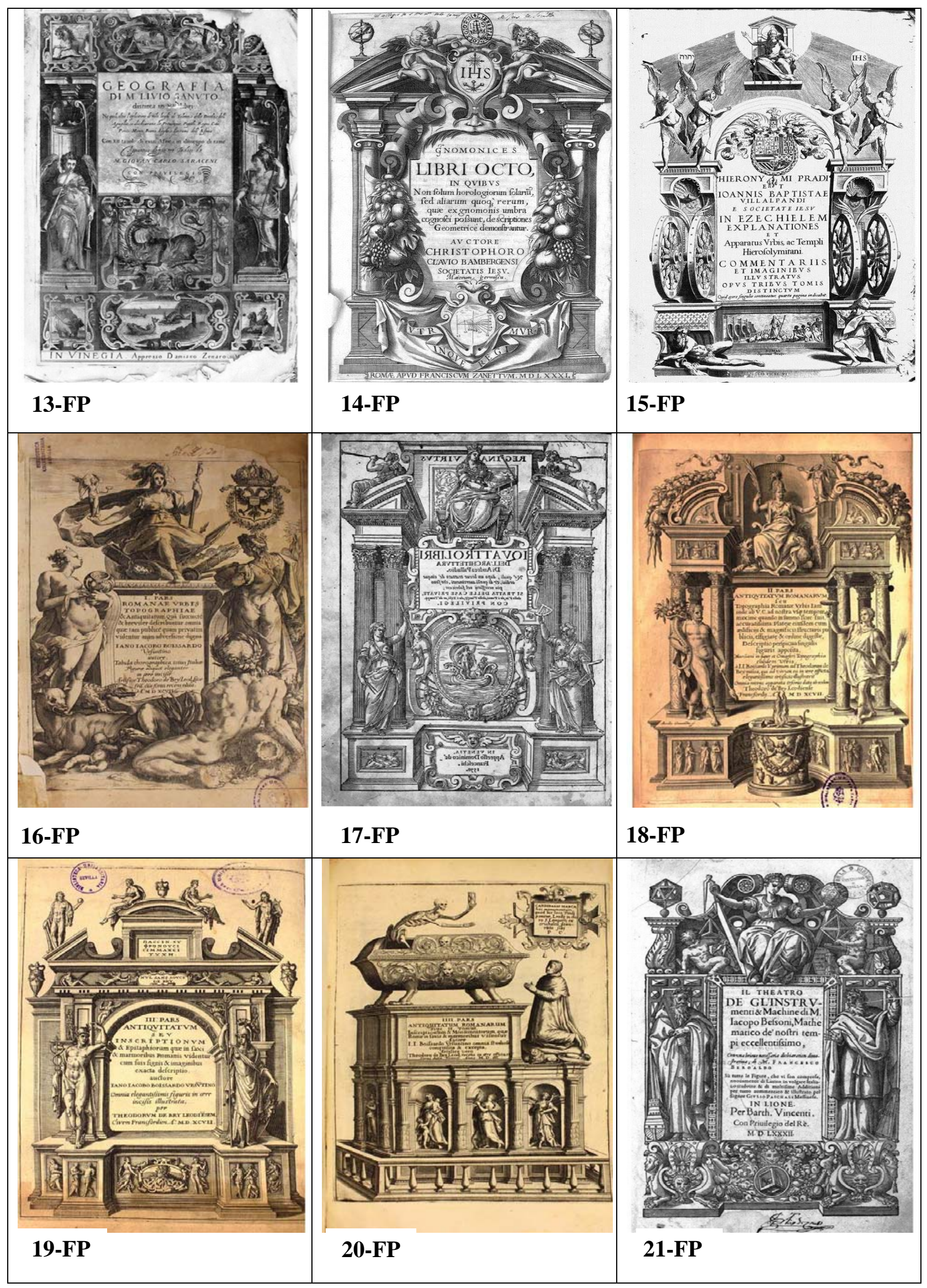




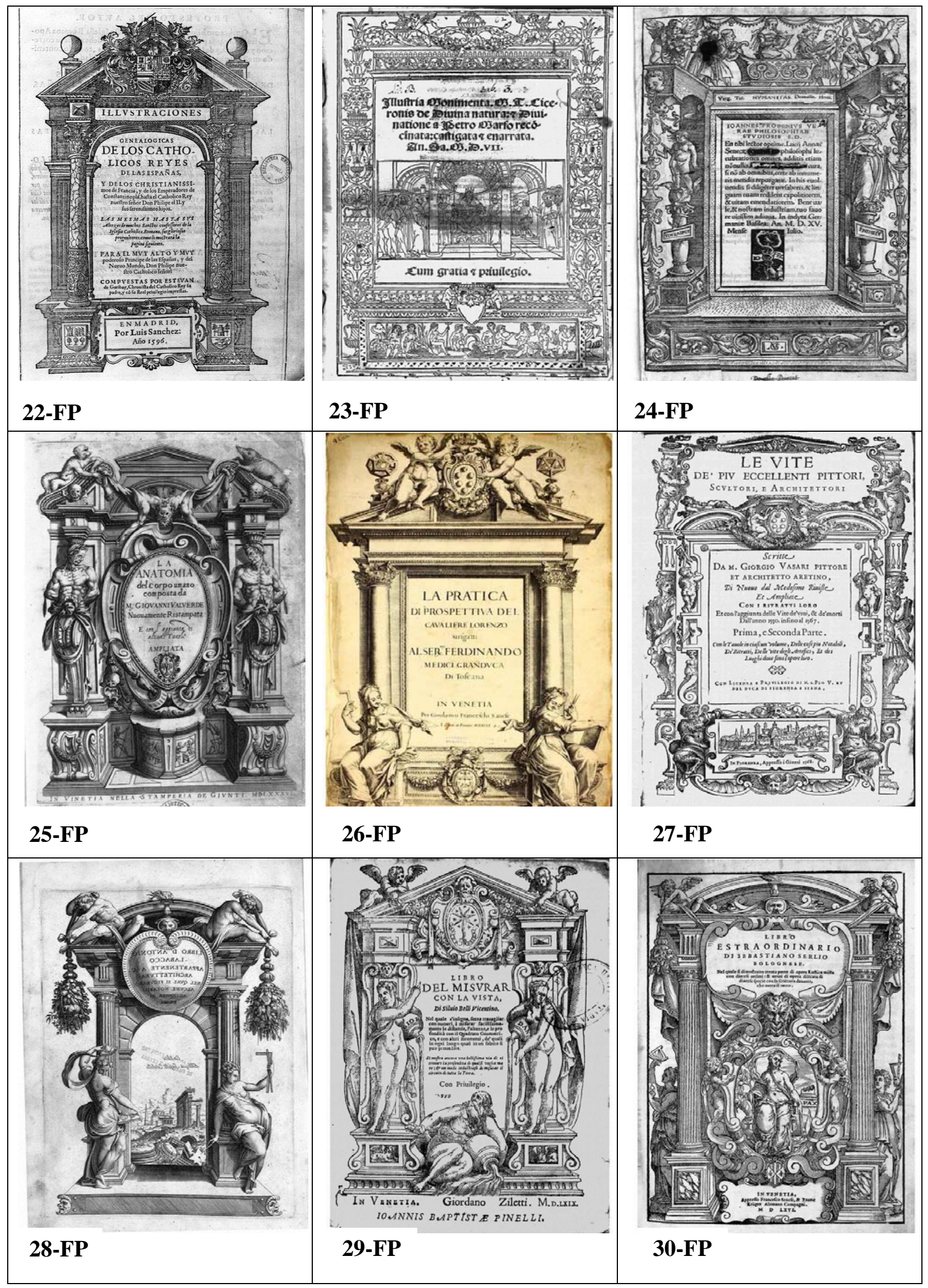




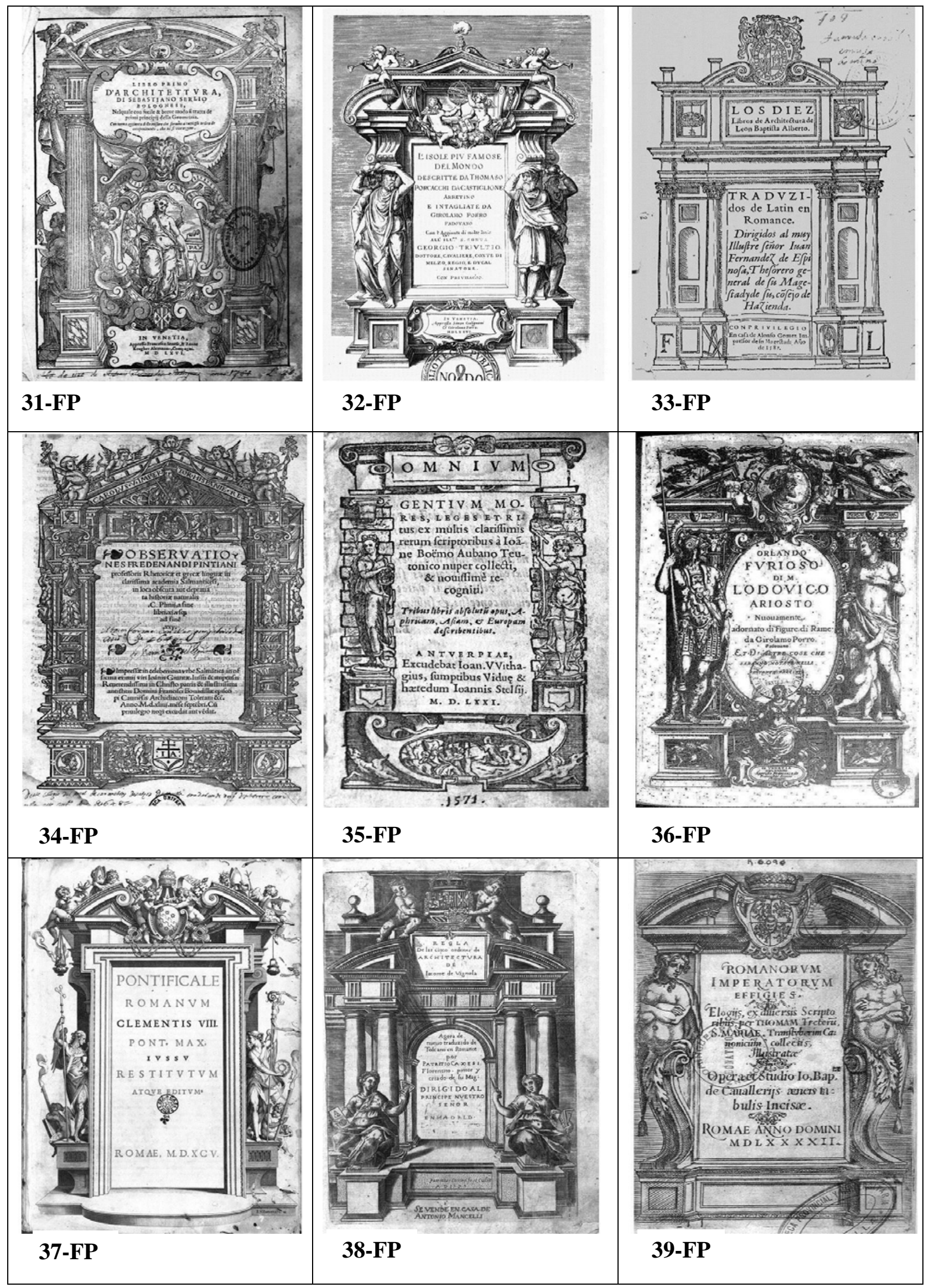




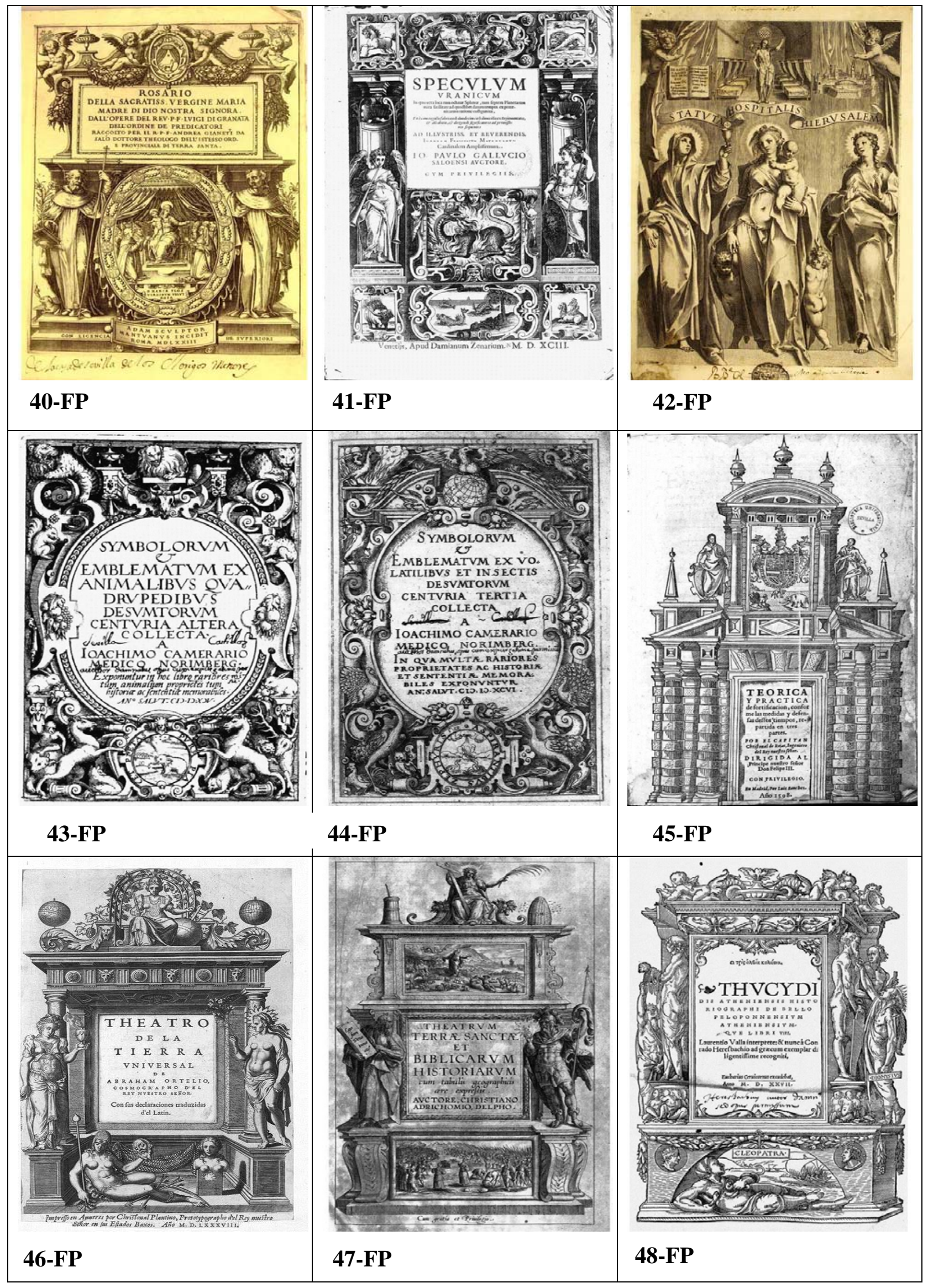




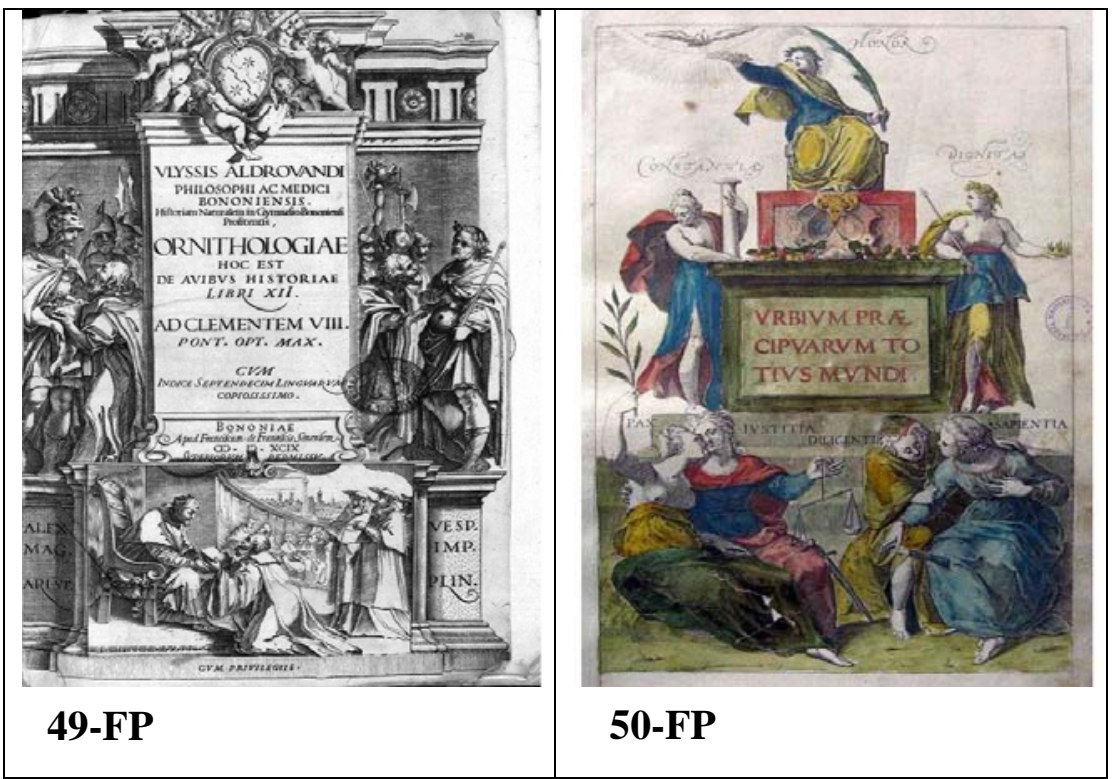




\section{Apéndice 2: referencias bibliográficas de las obras con frontispicios}

\section{Frontispicios con orlas arquitectónicas (FO)}

1-FO. Catonis disticha moralia Annotationibus quibusdam Antonij Nebrissensis illustrata. Dicta Sapientum. Mimi Publiani. Isocratis Parenaesis. Christiani Militis institutum Per Erasmu[m] Roterodamum. Apvd inclytam Granatam: [S.n.], 1553. A Res. 04/5/15.

2-FO. Comiença el libro llamado Vergel de oracion y monte de contemplación/hecho por un religioso de la orde[n] del bie[n]aue[n]turado padre scto Augusti ... Seuilla: en casa d[e] Anton Aluarez, 1544. A Res. 25/3/18.

3-FO. De co[n]cordantia catholica libri tres R. patris Nicolai de Cusa theologiae ac pontificii iuris professoris eximii.. Parisiis: in aedibus Ascensianis, 1514. A Res. 38/4/17.

4-FO. De erratis Orontii Finaei regii.../Petri Noni... Conimbricae: Ex Officina Ioannis Barrerii \& Ioannis Aluari, 1546. A Res. 07/4/08(2).

5-FO. De Navigatione libri tres: quibus Mathematicae disciplinae explicantur/ab Iacobo a Saa Equite Lusitano... Parisiis: ex officina Reginaldi Calderij \& Claudij eius filij, 1549. A Res. 31/6/09.

6-FO. Epistolas del glorioso doctor sant Hieronymo. Seuilla: En casa d'1 Jurado Jua[n] Varela de Salama[n]ca, 1532. A Res. 35/2/12.

7-FO. Expositio primi tractatus sumularum magistri Petri hispaniordinis predicatoru[rum]/ edita a fratre Augustino Ibarroya.... Hispali: In sua Excussit officina Bartholomeus Perez, 1533. A Res. 44/3/14(1).

8-FO. Historia imperial y Cesarea en la qual en suma se cotiene las vidas y hechos de todos los Cesares emp[er]adores de Roma... Seuilla: En casa de Jua[n] de Leo[n], 1545. A Res. 33/2/16.

9-FO. Hortus sanitatis, quatuor libris haec quae snbsequuntur complectens: De animalibus \& reptilibus, ... Argentorati: per Mathiam Apiarium, 1536. A Res. 04/3/18.

10-FO. Iacobi Peletarii ... in Euclidis Elementa Geometrica demonstrationum libri sex ... Lugduni: Apud Ioan. Tornaesium et Gul. Gazeium, 1557. A Res. 07/2/12.

11-FO. La philosophía vulgar/ de Juan de Mal Lara. Sevilla: [Fernando Diaz], 1568. G RA 090.

12-FO. La quarta parte del Vita Christi Cartuxano.../ [q el reuerendo padre fray Ambrosio Motesino...; ordenado por... Landulpho de Saxonia p[ro]fesso en la... cartuxa de... Argentina]. Emprimiose en... Seuilla: en la officina de Jacome Crōberger, 1551. A Res. 61/3/11(2).

13-FO. La segu[n]da parte del vita christi cartuxano/ [interpretado de latin en romance... de Castilla por Fray Ambrosio Montesino, de la orde de los frayles menores...]. Impressa en... Seuilla: ē las casas de Jacome Cromberger, 1551. A Res. 61/3/10(2).

14-FO. Liber de compositione mundi/Excelle[n]tissimi viri Pauli Veneti... Lugduni: Simon Vincentius: in edibus Antonij du Ry, 17 de Noviembre, 1525. A 336/131(2).

15-FO. Libri de re rustica/M. Catonis, M. Terentii Varronis, L. Iunii Moderati Columelle, Palladii Rutilii: quorum summam paginaseque[n]s indicabit. [Parisiis]: Venundantur Iodoco Badio Ascensio, 1529. A Res. 09/2/13(1).

16-FO. Los cinco libros de Seneca en Romance... Fue impresso... en la... vniversidad de Alcala de Henares: en casa de Miguel de Eguia, 1530. A Res. 06/3/19(1).

17-FO. M. Annei Lucani cordubensis pharsalia diligentissime/per G. Versellanum recognita... [Parissis]: venundatur ab ipso Ascensio \& Ioanne paruo, [1514]. A Res. 31/1/06.

18-FO. Opera Q. horatii flacci poete amoenissimi cum quatuor commentariis/Acronis, Porphirionis, Anto. Mancinelli, Iodoci Badij accurate repositis... Vaenundantur Parrisiis: Apud Ioannem Paruum..., 1517. A Res. 07/3/17(1).

19-FO. Opusculum de sphera mundi Ioannis de sacro busto/cu[m] additionibus \& familiarissimo com[m]e[n]tario Petri Ciruelli Darocensis...; intersertis etia[m] egregijs questionibus domini Petri de Aliaco. Fuit excussum hoc opusculum in Alma Complutensi Vniuersitate: apud Michaelem de Eguia ..., 1526. A Res. 52/4/24.

20-FO. Physica Pauli Veneti cum textu Argiropyli: Summa philosophie naturalis.../ Pauli Veneti... Lugduni: Simon Vincentius: in edibus Antonij du Ry, 6 de Septiembre, 1525. A 336/131(1).

21-FO. Phytognomonica Io. Baptistae Portae... octo libris contenta... Neapoli: Apud Horatium Saluianum, 1588. A Res. 44/3/20.

22-FO. Platonis Opera/a Marsilio Ficino traducta... [s.n., Paris]: Iodocus Badius, 1522. A Res. 05/1/01.

23-FO. Quaestiones et decisiones physicales insignium virorum: Alberti de Saxonia in Octo libros physicorum ... Parrhisii: a reuere[n]do M. Io. Buridano impressae aut rursus \& dilige[n]tius recognit[a]e: Impe[n]sis Iodoci Badii \& Conradi Resch, 1518. A Res. 25/2/04.

24-FO. Que hoc libro continentur: Nonii Marcelli peripathetici adfilium et de verborum proprietate compendium... Denundantur parrhisiis: in uicodiui Iacobi sub signo Pellican: de Marnef, 13 de Febrero, 1519. A 335/052(1).

25-FO. Questiones et decissiones physicales insignium virorum: Alberti de Saxonia in Octo libros physicorum ... Venundantur Lugduni: apud Iacobum Giuntam: apud Ioanne Moylin, 1534. A Res. 15/2/06. 
26-FO. Questiones Fra. Amadei Meygreti lugdunensis ordinis predicatorum in libros de c[o]elo [et] mu[n]do Aristotelis. [Paris] Venundantur Parrhisii in vico diui Jacobi sub intersignio Lilii Aurei: [Jehan Petit], 1514. A Res. 54/3/05(2).

27-FO. Reglas y arte [para] apre[n]der el oficio diuino. Seuilla: En casa de Jua[n] cromberger, 1535. A Res. 27/7/15(5).

28-FO. Tractado de la sphera_que compuso el Doctor Ioannes de Sacrobusto... En... Sevilla: En Casa de Juan de Leon, 1545. A Res. 05/5/09.

29-FO. Tratado da sphera com a theorica do sol et da Lua, e ho primeiro liuro da Geographia de Claudio Ptolomeo Alexandrino/tirados nouamente de latim em lingoagem pello Doutor Pero Nunes... Lisboa per Germao Galharde..., 1537. A Res. 07/4/08(1).

30-FO. Tratado muy prouechoso para todo fiel christiano que quisiere saber el efecto de las indulgencias y perdones. Seuilla: en la Enprenta de Juan cromberger, 1535. A Res. 27/7/15(4).

31-FO. Vergilius cum co[m]me[n]tarijs [et] figuris.. [Venetiis: ... per Gregorium de Gregoriis: impensis vero D. Lucae Antonii de Giunta, 1522 die 20 mensis nouembris]. A Res. 67/4/15.

32-FO. Visio[n] delectable de la philosophia [et] artes liberales: metaphisica y philosophia moral. Es impresso en ... Seuilla: En casa de Juan Cro[m]berger, 1538. A Re s. 72/3/18.

33-FO. Vita Christi Cartuxano...: [primera parte/compuesto por... Landulpho de la orden de la cartuxa. Seuilla: en casa [de] Jacome cro[m]berger, 1551. A Res. 61/3/10(1).

34-FO. Vita Christi Cartuxano...: [primera parte compuesto por... Landulpho de la orden de la cartuxa; interpretado de latin en romāce por... Fray Ambrosio Mōtesino de la ordē [de] los menores, por mādado de... dō Fernādo y doña Ysabel reyes de España]. Seuilla: en casa [de] Jacome cro[m]berger, 1551. A Res. 61/3/11(1).

\section{Frontispicios con planchas (FP)}

1-FP. Civitates orbis terrarum. [Liber primus]/[Georgius Braum et Franciscus Hogenbergius]. Coloniae Aggrippinae: Apud Petrum á Brachel: sumptibus auctorum, [ca. 1576]. A Res. 73/1/11.

2-FP. Constituciones synodales del Obispado de Cuenca. Hechas por el reuerendissimo señor Don Diego Ramirez de Villescula... [En la ciudad de Cuenca: Arte [et] industria de Francisco de Alfaro, 1531]. A Res. 45/4/25.

3-FP. D. And. Alciati Emblemata/Denuo ab ipso autore recognita, ac quae desiderabantur, imagini bus locupletata... Lugduni: apud Guilielmum Rovillé, 1566. A Res. 29/3/10.

4-FP. De praecipuis totius universi urbibus liber secundus/[Georgius Bruin, et Franciscus Hogenbergius] [S.1.: s.n., ca. 1575]. A Res. 73/1/12.

5-FP. Delle vite de' più eccellenti pittori scultori, e archittetori/Scritte da M. Giorgio Vasari...; Primo Volume della Terza Parte [-Secondo, et ultimo Volume della Terza Parte]. In Fiorenza: Appresso i Giunti, 1568. A Res. $19 / 3 / 25$.

6-FP. Dialogo llamado Democrates/co[m]puesto por el doctor Juan de sepulueda capella[n] y coronista de su S.C.C.M. del emp[er]ador; agora nueuamente inpresso. Fue impresso en la muy noble [et] muy Leal ciudad de Seuilla: en casa de Juan cro[m]berjer..., 1541, a 28 dias del mes de mayo. A Res. 27/3/06.

7-FP. Diffiniciones de la Orden y Caualleria de Alcantara, con relacion de su orige[n] y de los maestres que vuo en ella. Madrid: por Alonso Gomez, 1576. A Res. 37/2/11.

8-FP. Elucidatio fabricae ususque astrolabii/Ioanne Stoflerino...: iam denuo ab eodem uix aestima[n]dis sudoribus recognita dilige[n]ter locupletataq[ue]... Oppenheim: in aedibus Iacobi Cobelii, mense Martio, 1524. A 336/146(1).

9-FP. Euclidis Elementorum libri XV: unà cum scholiis antiquis/À Federico Commandino... nuper in latinum conuersi, commentariisque quibusdam illustrati. Pisauri: Iacobus Chriegher German: apud Camillum Francischinum, 1572. A Res. 66/4/07.

10-FP. Europae Totius Orbis Terrarum Partis Praestantissimae, Universalis et particularis descriptio.../ [Matthias Quad]. Coloniae: Ex officia typographica Jani Bussemechers, 1592. A Res. 04/4/21.

11-FP. Fastos magistratum et triumphorum romanorum ab urbe condita ad Augusti obitum ex antiquis tam numismatum quam marmorum monumentis restitutos/S.P.Q.R. Hubertus Goltzius ... dedicauit. Brugis Flandorum: excudebat Hubertus Goltzius, 1566. A Res. 45/2/09.

12-FP. Funerali Antichi di diversi Popoli et Nationi: forma, ordine, et pompa di sepolture, di essequie, di consecrationi antiche et d'altro/Descritti in Dialogo da Thomaso Porcacchi da Castiglione Arretino; con le Figure in Rame di Girolamo Porro Padovano. Venetia: appresso Simon Galignani de Karera, 1574. A Res. 53/5/08.

13-FP. Geografia di M. Livio Sanuto distinta in XII. Libri: ne'quali, oltre l'esplicatione di molti luoghi di Tolomeo e della Bussola e dell'Aguglia si dichiarano le provincie popoli regni città ... dell'Africa... In Vinegia: Appresso Damiano Zenaro, 1588. A Res. 02/1/08. 
14-FP. Gnomonices libri octo: in quibus non solum horologiorum solariu[m] sed aliarum quoq[ue] rerum... /auctore Christophoro Clauio... Romae: Apud Franciscum Zanettum, 1581. A Res. 45/1/05.

15-FP. Hieronymi Pradi et Ioannis Baptistae Villalpandi... In Ezechielem explanationes et apparatus vrbis ac templi Hierosolymitani. Romae: ex typographia Aloysij Zannetti: apud S. Marcum, 1596. A Res. 57/1/06-08.

16-FP. I Pars Romanae vrbis topographiae \& antiquitatum quà succinctè \& breuiter describuntur omnia quae tam publicè quam priuatim videntur anim-aduersione digna/Iano Iacobo Boissardo...autore... Impressum Francofurti: apud Iohannem Feyrabend: impensis Theodoro de Bry ..., 1597. A Res. 62/4/07(1).

17-FP. I quattro libri dell'architettura di Andrea Palladio, ne' quali, dopo un breue trattato de' cinque ordini,... In Ventia: appresso Dominico de Franceschi, 1570. G Arte R.07.T.25.

18-FP. II Pars Antiquitatum romanorum seu topographia Romanae vrbis .../ à I.I. Boissardo V. primum ad Theodorum de Bry missa... Francfordii: Typis Ioannis Saurij: impensis Theodori de Bry ..., 1597. A Res. 62/4/07(2).

19-FP. III Pars Antiquitatum seu inscriptionum \& epitaphiorum quae in saxi \& marmoribus Romanis..._auctore Iano Iacobo Boissardo... [Metz, Frankfurt]: Excussum Typis Abrahami Fabri...; [Frankfurt]: impensis Theodori Bryi ..., 1597 (1595). A Res.62/4/08(1).

20-FP. IIII Pars Antiquitatum romanarum siue II tomus inscriptionum \& monumentorum quae Romae in saxis \& marmoribus visuntur/autore I.I. Boissardo ...; Artifice vero Theodoro de Bry Leod. recèns in aere efficta, et foras dataTheodoro de Brij... Francf[orti]: [s.n.], 1598. A Res.62/4/08(2).

21-FP. Il theatro de gl'instrumenti \& machine/di M. Iacopo Bessoni... In Lione: Per Barth. Vincenti, 1582. A Res. $73 / 1 / 08$.

22-FP. llustraciones genealogicas de los Catholicos Reyes de las Españas y de los Christianissimos de Francia y de los Emperadores de Constantinopla .../compuestas por Esteuan de Garibay... En Madrid: por Luis Sanchez, 1596. A Res. 35/1/09.

23-FP. Illustria monimenta M.T. Ciceronis de Divina natura [et] divinatione/a Petro Marso reco[n]cinata, castigata [et] enarrata. Venetiis: per Lazarum Soardum, 1507 [1508]. A 336/158(1).

24-FP. Ioannes Frobenius verae philosophiae studiosos S.D. en tibi lector optime, Lucij Annaei Senecae.../additis etiam no[n]nullis Erasmi Roterodami cura, si no[n] ab omnibus, certe ab innumeris mendis repurgatae ... In inclyta Germaniae Basilea: Ioannes Frobenius, 1515. A Res. 15/4/15.

25-FP. La anatomia del corpo umano/composta da M. Giovanni Valverde. In Vinetia: Nella Stamperia de Giunti, 1586. A Res. 68/5/05(1).

26-FP. La Pratica di prospettiua del caualiere Lorenzo Sirigatti... Venetia: per Girolamo Franceschi Sanese ..., 1596. H Arte R.08.T.16.

27-FP. Le vite de' più eccellenti pittori, scultori e architettori/Scritte da M. Giorgio Vasari... Prima, e seconda parte. In Fiorenza: Appresso i Giunti, 1568. A Res. 19/3/24.

28-FP. Libro D'Antonio Labacco Appartenente All'Architettura, Nel Qual Si Figurano Alcune Notabili Antiquita Di Roma. Impresso In Roma: In Casa Nostra, 1559. G Arte R.09.T.05.

29-FP. Libro del misurar con la vista... nel quale s'insegna, senza travagliar con numeri, a misurar facilissimamente ledistancie, l'altezze, e le profondita con il quadrato geometrico... Venetia: Giordano Ziletti, 1569. A Res. $10 / 5 / 16$

30-FP. Libro estraordinario di Sebastiano Serlio bolognese, nel quale si dimostrano trenta porte di opera rustica mista con diuersi ordini \& uenti di opera dilicata... In Venetia: Appresso Francesco Senese, \& Zuane Krugher Alemano compagni, 1566. A Res. 18/4/03(2).

31-FP. Libro primo [-quinto] d'architettura di Sebastiano Serlio bolognese, nel quale con facile \& breue modo si tratta de primi principij della geometria; Con nuoua aggiunta delle misure che seruono a tutti gli ordini de componimenti, che ui si contengono. In Venetia: Appresso Francesco Senese, \& Zuane Krugher Alemanno, compagni, 1566. A Res. 18/4/03(1).

32-FP. L'isole piu famose del mondo/descritte da Thomaso Porcacchi da Castiglione aretino e intagliate da Girolamo Porro padovano con l'Aggiunta di molte Isole... In Venetia: Apresso Simon Galignani et Girolamo Porro: Appresso Giorgio Angelieri, a instantia di Simon Galignari de Karera, 1575. A Res. 11/3/01.

33-FP. Los diez libros de Architectura/de Leon Baptista Alberto; traduzidos de latin en romance... [Madrid]: En casa de Alonso Gomez..., 1582. A Res. 12/4/03 Arquitectura.

34-FP. Obseruationes Fredenandi Pintiani... in loca obscura aut deprauata historiae naturalis C. Plinij a fine libri xj vsq[ue] ad fine[n] xxv. Impressae in... vrbe Salma[n]tica: in officina... Ioa[n]nis Giuntae, iussu \& impensis... Domini Francisci Bouadillae..., 1544 me[n]se septe[m]bri. A Res. 59/3/17.

35-FP. Omnium gentium mores, leges \& ritus... Antuerpiae: Excudebat Ioan. VVithagius: sumptibus Vidu[a]e \& haeredum Ioannis Steelsij, 1571. A Res. 29/6/29.

36-FP. Orlando furioso/di M. Lodovico Ariosto. In Venetia: appresso Francesco de Franceschi Senese e compagni, 1584. A Res. 53/5/01.

37-FP. Pontificale Romanum Clementis VIII Pont. Max. iussu restitutum atque editum. Romae: apud Iacobum Lunam: impensis Leonardi Parasoli \& Sociorum, 1595. A Res. 44/1/02. 
38-FP. Regla de las cinco ordenes de architectura/de Iacome de Vignola; agora de nuevo traduzido de toscano en romance por Patritio Caxesi Florentino. Madrid: En Casa de Antonio Mancelli, 1593. Q Arm. 1 VIG/Reg3.

39-FP. Romanorum Imperatorum effigies/Elogijs, ex diuersis Scriptoribus, per Thomam Treteru[m] ... collectis, illustratae; Opera et studio Io. Baptae. de Cauallerijs aeneis tabulis incisae. Romae: [s.n.], 1592. A Res. $70 / 5 / 21$.

40-FP. Rosario della sacratiss. Vergine Maria .../Dall'opere del Reu. P.F. Luigi di Granata dell'Ordine de Predicatori... Romae: Appresso Giuseppe de gl'Angeli, 1573. A Res. 37/4/15Rosario.

41-FP. Speculum Uranicum: in quo vera loca tum octauae sphaerae.../Io. Paulo Gallucio Saloensi auctore Venetijs: Apud Damianum Zenarium, 1593. A Res. 01/2/04.

42-FP. Statuta Hospitalis Hierusalem. [S.1.: s.n., 1588?]. A Res. 77/2/08.

43-FP. Symbolorum \& emblematum ex animalibus quadrupedibus desumtorum centuria altera collecta/a Ioachimo Camerario... Norimbergae: excudebat Paulus Kaufmann, 1595. A Res. 12/5/01(2).

44-FP. Symbolorum \& emblematum ex volatilibus et insectis desumtorum centuria teria collecta/a Ioachimo Camerario... Noribergae: Excudebat Paulus Kaufmann, 1596. A Res. 12/5/02(1).

45-FP. Teorica y practica de fortificacion conforme las medidas y defensas destos tiempos: repartida en tres partes/por el capitan Christoual de Rojas... En Madrid: por Luis Sanchez, 1598. A Res. 72/4/18.

46-FP. Theatro de la tierra universal/de Abraham Ortelio...; con sus declaraciones traduzidas d'el latin. Impresso en Anvers: por Christoval Plantino ..., 1588. A Res. 73/1/03.

47-FP. Theatrum Terrae Sanctae et bibliarum historiarum: cum tabulis geographicis aere expressis/auctore Christiano Adrichomio Delpho. Coloniae Agrippinae: In Officina Birckmannica: sumptibus Arnoldi Mylij, 1593. A Res. $35 / 1 / 07$.

48-FP. Thucydidis atheniensis historiographi De bello peloponnesium atheniensiumque libri VIII/Laurentio Valla interprete ... [Coloniae]: Eucharius Ceruicornius excudebat: [et] aere M. Godefridi Hittorpii ..., 1527. A Res. $14 / 3 / 08(1)$.

49-FP. Vlyssis Aldrouandi... Ornithologiae hoc est de auibus historiae libri XII... Bononiae: Apud Franciscum de Franciscis...: Apud Io. Baptistam Bellagambam: Impensis... Francisci de Francisci..., 1599. A Res. 04/1/02.

50-FP. Vrbium praecipuarum totius mundi/[Georgius Bruin, et Franciscus Hogenbergius] [S.1.: s.n., ca. 1586]. A Res. $73 / 1 / 14$. 